\title{
Prediction of the Transporter-Mediated Drug-Drug Interaction Potential of Dabrafenib and Its Major Circulating Metabolites ${ }^{[}$
}

\author{
Harma Ellens, Marta Johnson, Sarah K. Lawrence, Cory Watson, Liangfu Chen, \\ and Lauren E. Richards-Peterson
}

\author{
Drug Metabolism and Pharmacokinetics, GlaxoSmithKline, King of Prussia, Pennsylvania
}

Received August 18, 2016; accepted November 15, 2016

\section{ABSTRACT}

The BRAF inhibitor dabrafenib was recently approved for the treatment of certain BRAF V600 mutation-positive tumors, either alone or in combination therapy with the mitogen-activated extracellular signal regulated kinase 1 (MEK1) and MEK2 inhibitor, trametinib. This article presents the dabrafenib transporter-mediated drug-drug interaction (DDI) risk assessment, which is currently an important part of drug development, regulatory submission, and drug registration. Dabrafenib and its major circulating metabolites (hydroxy-, carboxy-, and desmethyl-dabrafenib) were investigated as inhibitors of the clinically relevant transporters P-gp, BCRP, OATP1B1, OATP1B3, OCT2, OAT1, and OAT3. The DDI Guidance risk assessment decision criteria for inhibition of BCRP, OATP1B1 and OAT3 were slightly exceeded and therefore a minor DDI effect resulting from inhibition of these transporters remained possible. Biliary secretion is the major excretion pathway of dabrafenib-related material $\mathbf{( 7 1 . 1 \%}$ of orally administered radiolabeled dose recovered in feces), whereas urinary excretion was observed as well (22.7\% of the dose). In vitro uptake into human hepatocytes of the dabrafenib metabolites, but not of dabrafenib parent compound, was mediated, at least in part, by hepatic uptake transporters. The transporters responsible for uptake of the pharmacologically active hydroxy- and desmethyl dabrafenib could not be identified, whereas carboxy-dabrafenib was a substrate of several OATPs. Dabrafenib, hydroxy-, and desmethyl-dabrafenib were substrates of P-gp and BCRP, whereas carboxy-dabrafenib was not. Although a small increase in exposure to carboxy-dabrafenib upon inhibition of OATPs and an increase in exposure to desmethyldabrafenib upon inhibition of P-gp or BCRP cannot be excluded, the clinical significance of such increases is likely to be low.
Introduction

The RAS/RAF/MEK/ERK pathway is a critical proliferative pathway in many human cancers (Roberts and Der, 2007). Recently, advances have been made in the development of therapies that specifically target mutated proteins in these cell signaling pathways (Flaherty and McArthur, 2010; Eggermont and Robert, 2011; Heakal et al., 2011; Falchook et al., 2012). BRAF is one of three genes encoding RAF-serine/threonine kinases. Mutations in BRAF result in a constitutively active kinase that has at least ten times higher activity compared with wild type (Davies et al., 2002). The potent and specific BRAF inhibitors vemurafenib and dabrafenib have significantly improved response rates and overall survival in patients with metastatic melanoma with BRAF V600E or V600K mutations (Ugurel et al., 2016). Dabrafenib was approved in the US as a monotherapy for the treatment of BRAF V600E mutation-positive tumors in 2013 (Hauschild et al., 2012) and as combination therapy with the MEK inhibitor trametinib for the treatment of BRAF V600E or V600K mutation positive tumors in

This work was sponsored by GlaxoSmithKline Pharmaceuticals Inc. Dabrafenib is an asset of Novartis AG as of March 2, 2015

https://doi.org/10.1124/dmd.116.073932.

$\$$ This article has supplemental material available at dmd.aspetjournals.org.
2014 (Menzies and Long, 2014; Dossett et al., 2015). The combination of dabrafenib and trametinib resulted in a significant delay in the onset of resistance compared with vemurafenib, with a longer median progression free survival, as well as a decreased incidence of skin adverse events (especially skin tumors) associated with administration of BRAF V600E or V600K inhibitors (Robert et al., 2015).

Dabrafenib is highly absorbed, with an oral bioavailability of $95 \%$ (Denton et al., 2013). In the human radiolabel study, elimination was mainly via oxidative metabolism, with an estimated $72 \%$ of the administered radiolabeled dose eliminated as metabolites, $(49.3 \%$ in the feces and $22.7 \%$ in the urine) and $21.8 \%$ of the dose as parent in the feces (biliary secretion and unabsorbed material), with no parent detected in the urine (Bershas et al., 2013). The main metabolites found in excreta and in circulation were hydroxy-dabrafenib, carboxy-dabrafenib, and desmethyl-dabrafenib. Averages of $4.52,9.48$, and $14.4 \%$ of the administered dose of $\left[{ }^{14} \mathrm{C}\right]$ dabrafenib were recovered in the feces, and averages of $1.36,7.11$, and $2.13 \%$ were recovered in the urine, as hydroxy-, carboxy-, and desmethyl-dabrafenib, respectively (Supplemental Table; Bershas et al., 2013). The remainder of the radioactivity in these two matrices, other than unchanged parent, was largely in the form of further oxidative metabolites of desmethyl-dabrafenib, plus a glucuronide of hydroxy-dabrafenib (only in urine).

ABBREVIATIONS: 6-CFL, 6-carboxyfluorescein; $A \rightarrow B$, Apical to basolateral; $A \cup C$, area under the curve; $B \rightarrow A, B$ asolateral to apical; $B \rightarrow A / A \rightarrow B$ ratio, $\mathrm{P}_{\text {app } B \rightarrow A} / \mathrm{P}_{\text {app } A \rightarrow B}$; $B C R P$, breast cancer resistance protein; $\mathrm{CHO}$, Chinese hamster ovary cell line; DDI, drug-drug interaction; DMEM, Dulbecco's modified Eagle medium; DMF, dimethyl formamide; DMSO, dimethyl sulphoxide; DPBS, Dulbecco's phosphate-buffered saline; EMA, European Medicines Agency; FBS, fetal bovine serum; FDA, Food and Drug Administration, HBSS, Hanks balanced salt solution; $\left[{ }^{3} \mathrm{H}\right] \mathrm{EG}$, $\left[{ }^{3} \mathrm{H}\right]$ estradiol $17 \beta$-D-glucuronide; HEK, human embryonic kidney; $\left[{ }^{3} \mathrm{H}\right] \mathrm{ES},\left[{ }^{3} \mathrm{H}\right]$ estrone sulfate; $\left[{ }^{3} \mathrm{H}\right] \mathrm{PAH}$, $\left[{ }^{3} \mathrm{H}\right] \mathrm{p}$-aminohippuric acid; HPLC/MS/MS, liquid chromatography-tandem mass spectrometry; $\mathrm{K}_{\mathrm{m}}$, affinity constant; MDCK,, Madin Darby canine kidney cells; MDR1, multidrug resistance protein 1; OAT, organic anion transporter; OATP, organic anion transporting polypeptide; OCT, organic cation transporter; P450, cytochrome $\mathrm{P} 450$; $\mathrm{P}$-gp, P-glycoprotein; $\mathrm{P}_{\mathrm{app}}$, apparent permeability; $\mathrm{V}_{\max }$, maximum uptake rate. 
Carboxy-dabrafenib exposure [area under the curve (AUC)] at steady state is about 11 -fold higher than that of dabrafenib, whereas hydroxy-dabrafenib and desmethyl-dabrafenib exposures are significant as well, at 90 and 70\% of that of dabrafenib (Study BRF113683). Hydroxy-dabrafenib and desmethyl-dabrafenib are potent inhibitors of BRAF V600E or V600K with in vitro antiproliferative $\mathrm{IC}_{50}$ values that are only two- to five-fold higher than dabrafenib, whereas that of carboxy-dabrafenib is 17 - to 240 -fold higher (data on file). Therefore hydroxy- and desmethyl-dabrafenib are expected to contribute to the pharmacological activity of the parent drug.

The potential interaction of dabrafenib and circulating metabolites with cytochrome $\mathrm{P} 450$ enzymes (P450s) was assessed recently (Lawrence et al., 2014). Dabrafenib is metabolized by CYP2C8 and CYP3A4 to hydroxy-dabrafenib, which in turn is metabolized by CYP3A4 to carboxy-dabrafenib (Fig. 1). A victim DDI risk was identified for dabrafenib as a substrate of CYP2C8 and/or CYP3A4. Clinical DDI studies showed a 1.47-fold increase in dabrafenib exposure (AUC) upon coadministration with the CYP2C8 inhibitor gemfibrozil and 1.71-fold increase on coadministration with the CYP3A4 inhibitor ketoconazole (Suttle et al., 2014). The risk of dabrafenib and metabolites affecting the pharmacokinetics of sensitive substrates of CYP2C8, 2C9, and 2C19 through $\mathrm{P} 450$ inhibition was minor; however, a significant risk was highlighted as a consequence of dabrafenib's pregnane $\mathrm{X}$ receptor and constitutive androstane receptor (CAR)-mediated induction potential. Coadministration of dabrafenib with the CYP3A4 substrate midazolam indeed showed a $74 \%$ decrease in midazolam exposure, whereas coadministration with the CYP2C9 substrate warfarin showed a $37 \%$ decrease in exposure of S-warfarin (h//www.pharma.us.novartis.com/ sites/www.pharma.us.novartis.com/files/tafinlar.pdf).

The role of drug transporters in drug absorption, distribution, and elimination and the potential for pharmacokinetic DDIs through inhibition or induction of drug transporters is now well established. In 2010, the International Transporter Consortium published a transporter white paper summarizing key transporters involved in clinically significant DDIs (Giacomini et al., 2010). As concerns about transportermediated DDIs continue to rise, risk assessments are now an important part of drug development, regulatory submissions, and drug registrations (Elsby et al., 2011; Han, 2011; Zhang et al., 2011; Reese et al., 2016). Regulatory DDI guidance documents are available and indicate which transporters should be assessed for this risk during the drug development process (EMA, 2012; FDA, 2012). The studies presented here were conducted to assess the potential of dabrafenib and its major circulating metabolites hydroxy-dabrafenib, carboxy-dabrafenib, and desmethyldabrafenib to be a perpetrator or a victim of transporter-mediated pharmacokinetic DDIs and provide information for the drug label.

The criteria listed in the decision trees in the Food and Drug Administration (FDA) or European Medicines Agency (EMA) DDI guidances were slightly exceeded for inhibition of BCRP, OATP1B1, and OAT3. A drugdrug interaction study evaluating the effect of dabrafenib on rosuvastatin, a BCRP, OATP1B1, and OAT3 substrate, is currently ongoing. Because clearance of dabrafenib-related material is mainly via biliary secretion, dabrafenib and its metabolites were investigated as in vitro substrates of hepatic uptake and efflux transporters. Dabrafenib, hydroxy-dabrafenib, and desmethyl-dabrafenib were substrates of P-gp and BCRP, whereas carboxy-dabrafenib was not. Dabrafenib was not a substrate of hepatic uptake transporters. The uptake of hydroxy- and desmethyl-dabrafenib into hepatocytes was mediated, in part, by as yet unidentified uptake transporters, but these metabolites were shown not to be substrates of OATP1B1, OATP1B3, OATP2B1, or OCT1. Hepatocyte uptake of carboxy-dabrafenib, on the other hand, was largely mediated by OATPs. The worst case risk for hepatic uptake transportermediated victim DDIs for carboxy-dabrafenib was assessed using the static equation developed for transport inhibition (Zamek-Gliszczynski et al., 2009). Although a small increase in exposure to carboxy-dabrafenib upon inhibition of OATPs and an increase in exposure to desmethyldabrafenib upon inhibition of P-gp or BCRP cannot be excluded, the clinical significance of such increases is likely to be low.

\section{Materials and Methods}

\section{Chemicals and Reagents}

GF120918A (elacridar) and amprenavir were supplied by Chemical Development, GlaxoSmithKline (RTP, NC). $\left[{ }^{14} \mathrm{C}\right]$ cimetidine (ethanolic solution, specific activity $59.7 \mathrm{mCi} / \mathrm{mmol}$ ) was supplied by Selcia Limited, Essex, UK. [ $\left.{ }^{3} \mathrm{H}\right]$ digoxin (ethanolic solution, specific activity $185 \mathrm{GBq} / \mathrm{mmol}, 37 \mathrm{MBq} / \mathrm{ml}$ ) was supplied by Amersham Biosciences UK Ltd. [ $\left.{ }^{3} \mathrm{H}\right]$ estradiol $17 \beta$-D-glucuronide $\left(\left[{ }^{3} \mathrm{H}\right] \mathrm{EG}\right.$, ethanolic solution, specific activity $46.9 \mathrm{Ci} / \mathrm{mmol}),\left[{ }^{3} \mathrm{H}\right]$ estrone sulfate $\left(\left[{ }^{3} \mathrm{H}\right] \mathrm{ES}\right.$, specific activity $45 \mathrm{Ci} / \mathrm{mmol})$, and Hionic-Fluor were obtained from Perkin Elmer Life and Analytical Sciences (Boston, MA). $\left[{ }^{3} \mathrm{H}\right] p$-aminohippuric acid $\left(\left[{ }^{3} \mathrm{H}\right] \mathrm{PAH}\right.$ specific activity 40-60 Ci/mmol) was obtained from American Radiolabeled Chemicals, Inc. (St. Louis, MO). Rifamycin SV, cyclosporine A, ketoconazole, quinidine, and benzbromarone were procured from Sigma-Aldrich (St. Louis, MO). Montelukast was purchased from Cayman Chemical Company (Ann Arbor, MI), and rosuvastatin was from Sequoia Research (Pangbourne, UK). 6-Carboxyfluorescein (6-CFL) was procured from Invitrogen (Grand Island, NY). Dulbecco's modified Eagle's medium (DMEM) with glutamax, fetal bovine serum (FBS), penicillin/streptomycin, geneticin, L-proline, Hanks balanced salt solution (HBSS), and Eagle's minimum essential medium were obtained from Gibco Life Technologies (Grand Island, NY). InVitroGRO hepatocyte media was purchased from BioreclamationIVT (Baltimore, MD). The polarized Madin-Darby canine kidney (MDCKII) cell lines heterologously expressing human BCRP (MDCKII-hBCRP) or P-gP (MDCKII-hMDR1) were obtained from stocks purchased from the Netherlands Cancer Institute. The Chinese Hamster Ovary (CHO) cell line heterologously expressing OATP1B1 (CHO-OATP1B1) was obtained from stocks purchased on license from the University of Zurich. The human embryonic kidney cells (HEK-MSRII) and human OATP1B1, OATP1B3, OATP1A2, OATP2B1, OAT1, and OAT3 BacMam baculovirus transduction reagents were supplied by the Biologic Sciences group (BSci), GlaxoSmithKline (Collegeville, PA or Ware, UK). Control $\mathrm{S}_{2}$ cells and $\mathrm{S}_{2}$ cells expressing human OAT1 and OAT3 were obtained from Kyorin University School of Medicine, Tokyo, Japan (Kimura et al., 2002). Human Embryonic Kidney 293 (HEK293) control and OCT2 expressing cells were from Sekisui Medical Co., Ltd. Cryopreserved human hepatocytes were purchased from Celsis (Chicago, IL) and HEK293 transiently overexpressing OATP1B1*1a were supplied by Corning (Corning, NY). Twenty-four-well tissue culture plates were from Corning. All other reagents used in these investigations were reagent grade or higher and obtained from standard commercial suppliers.

\section{Cell Preparation and Culture Conditions}

Frozen cell stocks were prepared for the following cell lines: MDCKIIhMDR1, MDCKII-hBCRP, CHO-OATP1B1, and HEK-MSRII. Cells were grown to approximately $80 \%$ confluency in vented tissue culture flasks (adherent cells) or Erlenmeyer culture flasks (suspension cultures). Cells were harvested, centrifuged, resuspended to a density of $1-2 \times 10^{7}$ cells $/ \mathrm{ml}$ and subjected to a controlled-rate freeze cycle. The cryovials were transferred on dry ice to permanent storage in the vapor phase of a liquid nitrogen freezer.

Before the experiment, cells were rapidly thawed from frozen stocks at $37^{\circ} \mathrm{C}$ and transferred to sterile centrifuge tubes containing prewarmed media and centrifuged. After centrifugation, the pellet was suspended in the appropriate media and a small aliquot was removed for determining cell density and viability by Trypan Blue exclusion. Cells were then seeded into 24 -well plates at the appropriate cell density and incubated at $37^{\circ} \mathrm{C}$ with $5 \% \mathrm{CO}_{2}$ in a humidified incubator for a specified amount of time. Specific details for each transporter assay are described below.

MDCKII-hMDR1 or MDCKII-hBCRP cells were washed in DMEM with $10 \%$ FBS. After the final centrifugation, cells were seeded at a density of 1.2 to $1.6 \times 10^{5}$ cells/well in 24-well transwell plates in DMEM with $10 \%$ FBS and incubated for 3-4 days before use. 
Dabrafenib<smiles>CC(C)(C)c1nc(-c2cccc(NS(=O)(=O)c3c(F)cccc3F)c2F)c(-c2ccnc(N)n2)s1</smiles>

Hydroxy-dabrafenib

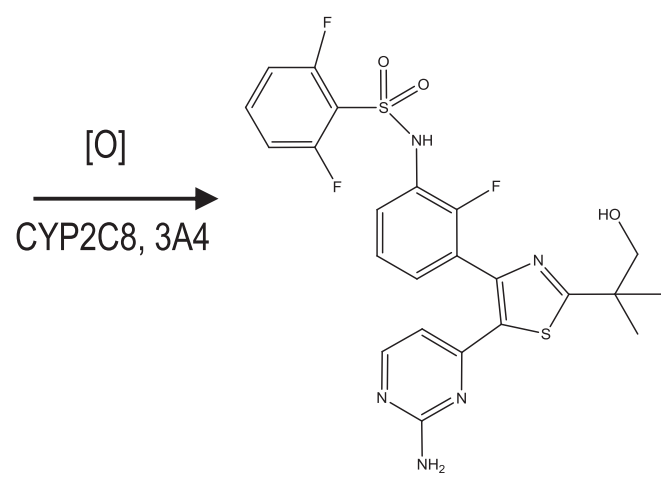

Carboxy-dabrafenib

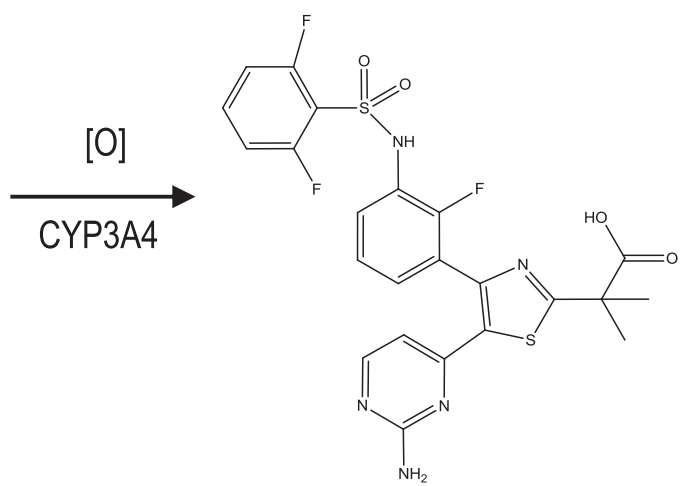

Desmethyl-dabrafenib

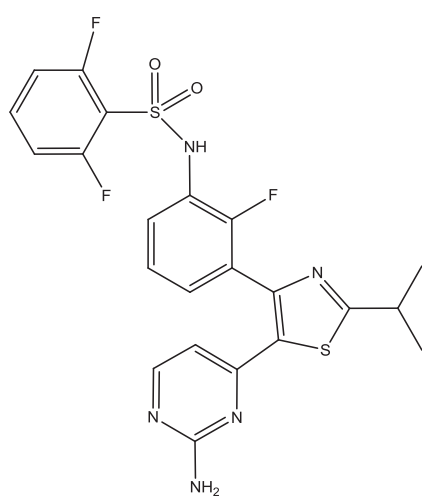

Fig. 1. Metabolic pathways of dabrafenib and its main circulating and excretory metabolites.

Cryopreserved human hepatocytes were thawed at $37^{\circ} \mathrm{C}$ and resuspended in 10 to $40 \mathrm{ml}$ of InVitroGRO CP plating media by gently inverting the tube several times. Cells were diluted to a density of $0.75 \times 10^{6}$ viable cells $/ \mathrm{ml}$. Five hundred microliters of this cell suspension was added to each well of a 24-well collagen coated plate (Becton Dickinson) to give a final density of $0.375 \times 10^{6}$ cells/well. Plates were placed into an incubator for approximately 4 hours to allow cell adherence before the experiment.

CHO-OATP1B1 cells were washed in prewarmed DMEM with glutamax. After centrifugation, cells were resuspended in cell culture medium [DMEM, 10\% FBS, $0.5 \%$ (v/v) 10,000 units/ml penicillin G sodium, 10,000 $\mu \mathrm{g} / \mathrm{ml}$ streptomycin, $0.1 \%$ (v/v) L-proline $(50 \mathrm{mg} / \mathrm{ml})$, and $0.7 \%(\mathrm{v} / \mathrm{v})$ Geneticin $(50 \mathrm{mg} / \mathrm{ml})]$ and seeded into 24-well noncoated polystyrene plates at a density of $1 \times 10^{6}$ cells/ well. The cell monolayers were used 2 days postseeding. OATP1B1 expression was induced for at least 24 hours before use with $5 \mathrm{mM}$ sodium butyrate.

HEK-OATP1B $1 * 1$ a cells were washed in prewarmed DMEM with $10 \%$ FBS and $1 \%$ Eagle's minimum essential medium nonessential amino acid solution and centrifuged. After centrifugation, the cells were resuspended to achieve a final cell density of $1 \times 10^{6}$ cells $/ \mathrm{ml}$. Cells were then seeded into poly-D-lysine coated polystyrene 24 -well assay plates at a density of $0.35 \times 10^{6}$ cells/well. Cells were incubated at $37^{\circ} \mathrm{C}$ with no humidity for 4 hours. Media was aspirated and cells were re-fed with $400 \mu$ l DMEM media supplemented with sodium butyrate (final concentration $5 \mathrm{mM}$ ). Cells were cultured for approximately 24 hours with no humidity before use in transport assays.

HEK-MSRII cells were washed and resuspended at a density of $1 \times 10^{6}$ cells $/ \mathrm{ml}$ in prewarmed DMEM-F12 with $10 \%$ FBS containing geneticin $(0.4 \mathrm{mg} / \mathrm{ml})$ and sodium butyrate $(2 \mathrm{mM})$. BacMam (Kost et al., 2010) reagent containing cDNA for human OATP1B3, OATP1A2, OATP2B1, OAT1, or OAT3 was added to the cell suspension to give the required multiplicity of infection. Cells were then seeded into poly-D-lysine coated polystyrene 24-well assay plates at a density of $4 \times 10^{5}$ cells/well for OATP1B3, OATP1A2, or OATP2B1 and $5 \times 10^{4}$ cells/well for OAT1 or OAT3. Cells were cultured for approximately 48 hours before use in transport assays.

Control S2 cells and S2 cells expressing OAT1 and OAT3 were cultured in 75- $\mathrm{cm}^{2}$ bottom flasks in RITC80-7 containing 5\% FBS, $10 \mathrm{mg} / \mathrm{L} \mathrm{EGF} \mathrm{(epidermal}$ growth factor), 80 units $/ \mathrm{mL}$ insulin, and $10 \mathrm{~g} / \mathrm{L}$ transferrin and subjected to passage every 2 to 3 days. The cells were trypsinized with $0.05 \%$ trypsin-EDTA, resuspended in culture medium and seeded in 24 -well non-collagen coated plates at a density of 2.4 to $4.1 \times 10^{5}$ cells/well 48 hour before use in transport assay.

Control HEK293 cell and HEK293 cells expressing OCT2 were cultured in $75-\mathrm{cm}^{2}$ bottom flasks in DMEM containing $10 \% \mathrm{FBS}, 1 \%$ L-glutamine, and $1 \%$ antibiotic-antimycotic (10,000 units/ml penicillin G sodium, $10,000 \mu \mathrm{g} / \mathrm{ml}$ streptomycin sulfate and $25 \mu \mathrm{g} / \mathrm{ml}$ amphotericin B as Fungizone in $0.85 \%$ saline) and subjected to passage every 3 to 4 days. The cells were washed with $1 \mathrm{ml}$ of PBS and then trypsinized with $0.25 \%$ trypsin EDTA. The cells were seeded in collagen I-coated 24 -well plates at a density of 2.4 to $2.6 \times 10^{5}$ cells/well and incubated for 48 hours before use in inhibition studies.

\section{In Vitro Transporter Assays}

P-gp and BCRP Inhibition Studies. Inhibition of P-gp-mediated transport of $\left[{ }^{3} \mathrm{H}\right]$ digoxin $(30 \mathrm{nM})$ was assessed by determining $[\mathrm{B} \rightarrow \mathrm{A}]$ transport in the absence or presence of increasing concentrations of dabrafenib (range: 0.3-100 $\mu \mathrm{M}$ ), hydroxy-dabrafenib, and desmethyl-dabrafenib (range: $0.1-100 \mu \mathrm{M}$ ) and carboxy-dabrafenib $(0.08-80 \mu \mathrm{M})$ over a 90 -minute incubation period. BCRPmediated transport of $\left[{ }^{14} \mathrm{C}\right]$ cimetidine $(100 \mathrm{nM})$ was assessed by determining $[\mathrm{B} \rightarrow \mathrm{A}]$ transport in the absence or presence of increasing concentrations of 
dabrafenib (range: 0.3-100 $\mu \mathrm{M}$ ), hydroxy-dabrafenib, carboxy-dabrafenib, and desmethyl-dabrafenib (range: 0.6-200 $\mu \mathrm{M}$ ) over a 90-minute incubation period. In the incubations with dabrafenib $(100 \mu \mathrm{M})$ and desmethyldabrafenib $(200 \mu \mathrm{M})$, the monolayer integrity in both test systems was affected, as indicated by increased permeability of the paracellular permeability marker Lucifer yellow to $>50 \mathrm{~nm} / \mathrm{s}$, and therefore these data points were excluded. Incubations were performed in triplicate. Incubation media were prepared for each concentration of test compound, including a no inhibition control (no test compound added) and a complete inhibition control (2 $\mu$ M GF120918), by diluting stock solutions of dabrafenib, hydroxydabrafenib, desmethyl-dabrafenib (stocks in DMSO), and carboxy-dabrafenib (stock in HPLC grade water) with transport medium (DMEM, with L-glutamine, $25 \mathrm{mM}$ HEPES, and pyridoxine- $\mathrm{HCl}$ but without phenol red and sodium pyruvate). The MDCKII-hMDR 1 or MDCK-hBCRP cell monolayers were preincubated for 20 minutes at $37^{\circ} \mathrm{C}$ (on a plate shaker at approximately $70 \mathrm{rpm}$ ) with control media, media containing test compound, or $2 \mu \mathrm{M}$ GF120918, as appropriate, by filling both apical $(0.45 \mathrm{ml})$ and basolateral $(1.3 \mathrm{ml})$ wells. At the end of the preincubation period, media were removed and wells were refilled with fresh incubation media containing test compounds and controls. The basolateral media also contained $\left[{ }^{3} \mathrm{H}\right]$ digoxin $(30 \mathrm{nM})$ or $\left[{ }^{14} \mathrm{C}\right]$ cimetidine $(100 \mathrm{nM})$ as well as Lucifer yellow $(100 \mu \mathrm{M})$. Plates were incubated at $37^{\circ} \mathrm{C}$ on a plate shaker for 90 minutes as described above. Upon completion of the incubation, $100 \mu \mathrm{l}$ samples were taken from both apical and basolateral compartments and transferred into 96-well Lumaplates. Plates were dried in a drying cabinet overnight and analyzed for total radioactivity using a Top count NXT microplate scintillation and luminescence counter (Perkin Elmer). Lucifer yellow concentration in the apical compartments was determined using a SpectraMax Gemini fluorescence microplate reader at wavelengths of $\lambda_{\mathrm{ex}} 430 \mathrm{~nm}$ and $\lambda_{\mathrm{em}} 538 \mathrm{~nm}$. Apparent passive permeability of Lucifer yellow was calculated as described in the calculations section below.

P-gp and BCRP Substrate Studies. The MDCKII-hMDR1 or MDCKIIhBCRP cell monolayers were preincubated for 20 minutes $\left(37^{\circ} \mathrm{C}\right)$ with transport media (on a plate shaker as described above) in the absence or presence of $2 \mu \mathrm{M}$ GF120918 (P-gp and BCRP inhibitor). Transport of $5 \mu \mathrm{M}$ dabrafenib, hydroxydabrafenib, carboxy-dabrafenib, or desmethyl-dabrafenib, prepared from stock solutions in DMF and diluted in transport media as described previously, was then assessed in two directions (apical to basolateral $[\mathrm{A} \rightarrow \mathrm{B}]$ and basolateral to apical $[\mathrm{B} \rightarrow \mathrm{A}])$ in the absence and presence of $2 \mu \mathrm{M}$ GF120918. P-gp studies were conducted in duplicate, whereas BCRP studies were performed in triplicate. Samples were removed from the apical and basolateral compartments after 90-minute incubation and analyzed for test compound concentration by liquid chromatography-tandem mass spectrometry (LC/MS/MS). Amprenavir $(5 \mu \mathrm{m})$ and $\left[{ }^{14} \mathrm{C}\right]$ cimetidine $(3 \mu \mathrm{M})$ were used as positive control substrates for P-gp and $\mathrm{BCRP}$, respectively, to ensure assay functionality. Lucifer yellow permeability was assessed in the same transport direction as the test compounds, as described for the transport inhibition experiments above. Efflux transporter inhibition and substrate experiments were regarded as valid where quality control parameters were within acceptable limits. Acceptable values for the P-gp and BCRP inhibition and substrate assays were Lucifer yellow permeability $\leq 50 \mathrm{~nm} / \mathrm{s}$; digoxin, amprenavir, or cimetidine mass balance 80-120\%; digoxin or cimetidine $\mathrm{B}>\mathrm{A}$ transport rate $\geq 1.5 \mathrm{pmol}$ transported $/ \mathrm{cm}^{2} / \mathrm{h}$; digoxin, amprenavir, or cimetidine transport rate in the presence of $2 \mu \mathrm{M} \mathrm{GF} 120918 \leq 30 \%$ of uninhibited rate. A compound was considered a P-gp or BCRP substrate when the efflux ratio was $>2$ in the absence of GF120918 and close to 1 in the presence of GF120918.

Organic Anion Transporting Polypeptides 1B1 and 1B3 (OATP) Inhibition Studies. The inhibition of human OATP1B1 or OATP1B3 was determined using CHO-OATP1B1 or HEK-MSRII cells, transduced with BacMam baculovirus containing human OATP1B1 or OATP1B3. Cell monolayers were preincubated in triplicate $\left(37^{\circ} \mathrm{C}\right)$ for 15 to 30 minutes in $1 \mathrm{ml}$ transport medium (DPBS) in the absence or presence of increasing concentrations of dabrafenib or its metabolites (range: $0.01-100 \mu \mathrm{M}$, respectively) or the positive control inhibitor rifamycin $(10 \mu \mathrm{M})$. After removal of preincubation media, cells were incubated at $37^{\circ} \mathrm{C}$ with the positive control substrate $\left[{ }^{3} \mathrm{H}\right] \mathrm{EG}$ $(0.02 \mu \mathrm{M})$ in the presence of test compound concentrations as described above. The incubation time was 5 minutes for CHO-OATP1B1 cells, 3 minutes for HEK-OATP1B1 cells, and 10 minutes for HEK-OATP1B3 cells. $\left[{ }^{3} \mathrm{H}\right] \mathrm{EG}$ uptake was terminated by rinsing rapidly with cold DPBS before cell lysis with $400 \mu$ l of $1 \%(\mathrm{v} / \mathrm{v})$ Triton $\mathrm{X}-100$. The $\mathrm{IC}_{50}$ values were determined as described in the calculations section below. Dabrafenib, at a concentration of $100 \mu \mathrm{M}$, decreased cell viability and therefore data from that concentration was excluded. Experiments were regarded as valid where quality control parameters were within acceptable limits. Acceptable values for the OATP1B1 and OATP1B3 assays are: $\geq 3$ - fold signal-to-noise (average probe substrate uptake rate in uninhibited control wells/average uptake in rifamycin inhibited wells).

Organic Cation Transporter 2 Inhibition Studies. The potential of dabrafenib, hydroxy-dabrafenib, carboxy-dabrafenib and desmethyl-dabrafenib to inhibit human organic cation transporter 2 inhibition (OCT2) was determined in a HEK293 cell line stably expressing OCT2 and in control cells. Cell monolayers were preincubated in triplicate $\left(37^{\circ} \mathrm{C}\right)$ for 15 minutes with $300 \mu \mathrm{L}$ HBSS in the absence or presence of increasing concentrations of test compound (range 0.003 $50 \mu \mathrm{M})$ or the positive control inhibitor quinidine $(300 \mu \mathrm{M})$. After preincubation, the buffer was replaced with $300 \mu \mathrm{l}$ of HBSS containing the positive control substrate $\left[{ }^{14} \mathrm{C}\right]$ metformin $(10 \mu \mathrm{M})$ in the absence or presence of increasing concentrations of test compound or quinidine. Each mixture was incubated at $37^{\circ} \mathrm{C}$ for 2 minutes. After incubation, each solution was removed and the cells were washed with $1 \mathrm{ml}$ of ice-cold $0.2 \%$ BSA-PBS once and $1 \mathrm{ml}$ of ice-cold PBS twice. All the PBS was removed and $0.1 \mathrm{~mol} / \mathrm{l} \mathrm{NaOH}(0.5 \mathrm{ml})$ was added and mixed by pipetting to lyse the cells. The cell lysate was collected and mixed with $10 \mathrm{ml}$ of Hionic-Fluor (Perkin Elmer) scintillation fluid and was measured by a liquid scintillation counter (LSC). $\left[{ }^{14} \mathrm{C}\right]$ metformin cleared volume was calculated as [uptake amount $(\mathrm{dpm} /$ well $) /$ protein amount $(\mathrm{mg}$ protein/well $) \times$ initial $\left[{ }^{14} \mathrm{C}\right]$ metformin concentration $\left.(\mathrm{dpm} / \mu \mathrm{l})\right]$. The \% inhibition at each inhibitor concentration was then calculated by subtracting cleared volume in control cells

TABLE 1

Inhibition of P-gp, BCRP, OATP1B1, OATP1B3, OCT2, OAT1, and OAT3 by dabrafenib and metabolites

\begin{tabular}{|c|c|c|c|c|c|c|}
\hline Transporter & \multicolumn{4}{|c|}{$\mathrm{IC}_{50}(\mu \mathrm{M})$} & Control Inhibitors & Probe Substrates \\
\hline P-gp & $>30^{a}$ & $>100$ & $>80$ & $>100$ & $2 \mu \mathrm{M} \mathrm{GF} 120918$ & $30 \mathrm{nM}\left[{ }^{3} \mathrm{H}\right]$ digoxin \\
\hline OATP1B3 & $4.7^{e}$ & 23 & 20 & 4.3 & $10 \mu \mathrm{M}$ Rifamycin & $0.02 \mu \mathrm{M}\left[{ }^{3} \mathrm{H}\right] \mathrm{EG}$ \\
\hline OAT1 & 6.9 & 29 & $65 \% @ 100^{f}$ & 10 & $30 \mu \mathrm{M}$ Benzabromarone & $5 \mu \mathrm{M}$ 6-CFL \\
\hline OAT3 & 3.4 & 7.3 & 9.0 & 3.4 & $30 \mu \mathrm{M}$ Benzabromarone & $5 \mu \mathrm{M}$ 6-CFL \\
\hline
\end{tabular}

EG, estradiol $17 \beta$-D-glucuronide; 6-CFL, 6-carboxyfluorescein.

${ }^{a}$ Highest test concentration $(100 \mu \mathrm{M})$ of dabrafenib did not meet the Lucifer yellow assay acceptance criteria $\left(\mathrm{P}_{7.4}>50 \mathrm{~nm} / \mathrm{s}\right)$, therefore data point excluded.

${ }^{b}$ Dabrafenib inhibited human BCRP in vitro by 52 and $44 \%$ at concentrations of 10 and $30 \mu \mathrm{M}$, respectively. The amount of inhibition was not sufficient to calculate an IC $\mathrm{C}_{50}$ value

${ }^{c}$ Carboxy-dabrafenib inhibited human BCRP in vitro by $42 \%$ at the highest test concentration of $200 \mu \mathrm{M}$. The amount of inhibition was not sufficient to calculate an IC $\mathrm{C}_{50}$ value.

${ }^{d}$ Highest test concentration $(200 \mu \mathrm{M})$ of desmethyl-dabrafenib did not meet the Lucifer yellow assay acceptance criteria $\left(\mathrm{P}_{7.4}>50 \mathrm{~nm} / \mathrm{s}\right)$; therefore data point not included.

${ }^{e}$ Highest test concentration $(100 \mu \mathrm{M})$ of dabrafenib caused a decrease in cell viability $(>20 \%)$; therefore, data point was not included.

${ }^{f}$ Carboxy-dabrafenib inhibited human OAT1 in vitro by $65 \%$ at the highest test concentration of $100 \mu \mathrm{M}$. The amount of inhibition was not sufficient to calculate an IC ${ }_{50}$ value

${ }^{g}$ Highest concentration tested of parent and metabolites was $50 \mu \mathrm{M}$. 
from cleared volume in OCT2-expressing cells. The $\mathrm{IC}_{50}$ values were determined as described in the calculations section below. Acceptable values for the OCT2 inhibition are cleared volume of probe substrate in transporter expressing cells/cleared volume of probe substrate in control cells $\geq 4$.

Organic Anion Transporter Inhibition Studies (OAT1 and OAT3). The potential of dabrafenib, hydroxy-dabrafenib, carboxy-dabrafenib, and desmethyldabrafenib to inhibit human OAT1 and OAT3 was determined in HEK-MSRII cells transduced with OAT1 or OAT3 using BacMam. Cell monolayers were preincubated in triplicate $\left(37^{\circ} \mathrm{C}\right)$ for 15 minutes in $200 \mu \mathrm{l}$ transport medium in the absence and presence of increasing concentrations of dabrafenib and metabolites $(0.027-100 \mu \mathrm{M})$ or control inhibitor benzbromarone $(30 \mu \mathrm{M})$. Following removal of preincubation media, cells were incubated with the probe substrate 6-carboxyfluorescein (6-CFL; $5 \mu \mathrm{M}$ ) in the absence or presence of increasing test compound concentrations or benzbromarone for 5 minutes at $37^{\circ} \mathrm{C}$. The incubation was terminated by washing $4 \times$ with $1 \mathrm{ml}$ of ice-cold PBS and uptake of 6-CFL was determined by measuring fluorescence using a FLUOstar Galaxy (BMG Labtechnologies, Offenburg, Germany) at an excitation wavelength of $485 \mathrm{~nm}$ and emission wavelength of $535 \mathrm{~nm}$. The $\mathrm{IC}_{50}$ values for OAT1 and OAT3 were calculated as described in the calculations section below. Acceptable values for the OAT1 and OAT3 assays are average probe substrate uptake in absence of inhibitor/ average probe substrate uptake in presence of benzbromarone $\geq 5$-fold The results of the in vitro inhibition studies are listed in Table 1.

Transporter-Mediated Uptake in Hepatocytes. Cryopreserved human hepatocytes were preincubated in triplicate at $37^{\circ} \mathrm{C}$ for 15 to 30 minutes in $1 \mathrm{ml}$ transport medium (DPBS with $1 \%$ DMSO or DMF at $37^{\circ} \mathrm{C}$ ) with or without a cocktail of hepatic uptake transporter inhibitors. The compounds selected for the inhibitor cocktail included the OATP1B1 and OATP1B3 inhibitor rifamycin SV (Roberts and Der, 2007), the OATP1B1 and OATP1B3 inhibitor cyclosporine A (Falchook et al., 2012), the OATP2B1 inhibitor montelukast (Shirasaka et al., 2012), and the OCT1 inhibitor quinidine (Umehara et al., 2008) at a final concentration of $10 \mu \mathrm{M}$ each. Uptake of dabrafenib $(0.3$ and $1.0 \mu \mathrm{M})$, hydroxydabrafenib $(0.5$ and $1.0 \mu \mathrm{M})$, carboxy-dabrafenib (1 and $30 \mu \mathrm{M})$, and desmethyldabrafenib $(0.3$ and $1.0 \mu \mathrm{M})$ was then determined as a function of time and in the absence and presence of the transporter inhibitor cocktail. Hydroxy-dabrafenib $(0.35 \mu \mathrm{M})$ and desmethyl-dabrafenib $(0.06 \mu \mathrm{M})$ were further assessed as OCT1 substrates in human hepatocytes by incubating in the absence and presence of the OCT1 inhibitor imipramine $(10 \mu \mathrm{M})$. The low substrate concentrations were chosen based on detection limit of the LC/MS/MS assay.

Rosuvastatin $(5 \mu \mathrm{M})$ or $\left[{ }^{14} \mathrm{C}\right]$ metformin $(5 \mu \mathrm{M})$ were added to separate wells as positive control substrates to demonstrate hepatocyte OATP or OCT1 function, respectively. Rosuvastatin uptake was measured over 5 minute in the absence and presence of the inhibitor cocktail, whereas $\left[{ }^{14} \mathrm{C}\right]$ metformin uptake was measured over 15 minutes in the absence and presence of imipramine.

Uptake studies were terminated by rinsing rapidly with cold DPBS before cell lysis with water. Cell lysates were extracted by liquid-liquid extraction with ethyl acetate, followed by LC/MS/MS analysis to determine dabrafenib, hydroxy-dabrafenib, desmethyl-dabrafenib, and rosuvastatin concentrations. For uptake of $\left[{ }^{14} \mathrm{C}\right]$ metformin, cells were lysed with $1 \%$ Triton-X and contents of each well were analyzed by LSC.

Individually Expressed Transporter Uptake Studies (OATP1B1, 1B3, 1A2, and 2B1). Transporter-mediated uptake of hydroxy-dabrafenib ( 0.3 and $1 \mu \mathrm{M})$, carboxy-dabrafenib $(2 \mu \mathrm{M})$, and desmethyl-dabrafenib $(0.3$ and $1 \mu \mathrm{M})$ was investigated in HEK-OATP1B1-, OATP1B3-, and OATP1A2-expressing and control cells, whereas hydroxy-dabrafenib and desmethyl-dabrafenib were also investigated in HEK-OATP2B1-expressing and control cells. Triplicate cell monolayers were preincubated at $37^{\circ} \mathrm{C}$ for $15-30$ minutes in $1 \mathrm{ml}$ transport medium with 1\% DMSO (DPBS for OATP1B3, 1A2, and 2B1 or HBSS for OATP1B1) in the absence or presence of transporter inhibitors: $10 \mu \mathrm{M}$ rifamycin (OATP1B1 and 1B3), $10 \mu \mathrm{M}$ ketoconazole (OATP1A2), and $10 \mu \mathrm{M}$ montelukast (OATP2B1). The uptake of each compound or positive control substrate $\left(\left[{ }^{3} \mathrm{H}\right] \mathrm{EG}\right.$ $0.02 \mu \mathrm{M}$ for OATP1B1 or OATP1B3 and $\left[{ }^{3} \mathrm{H}\right]$ estrone sulfate $0.02 \mu \mathrm{M}$ for OATP1A2 or OATP2B1) was then determined at $0.5,1,1.5,2,5,10,30$, and 60 minutes in the absence or presence of the inhibitors. At the indicated time points, cells were washed rapidly with cold buffer as described above for OATP inhibition studies and lysed with water or $1 \%$ Triton- $X$ if wells contained radiolabeled concentration of the test compounds in the cell lysates determined by LC/MS/MS or LSC as described above. Signal-to-noise ratio or probe substrate uptake in the absence of inhibitor/probe substrate uptake in the presence of inhibitor was between three- and sixfold in hepatocytes as well as in cells expressing individual transporters.

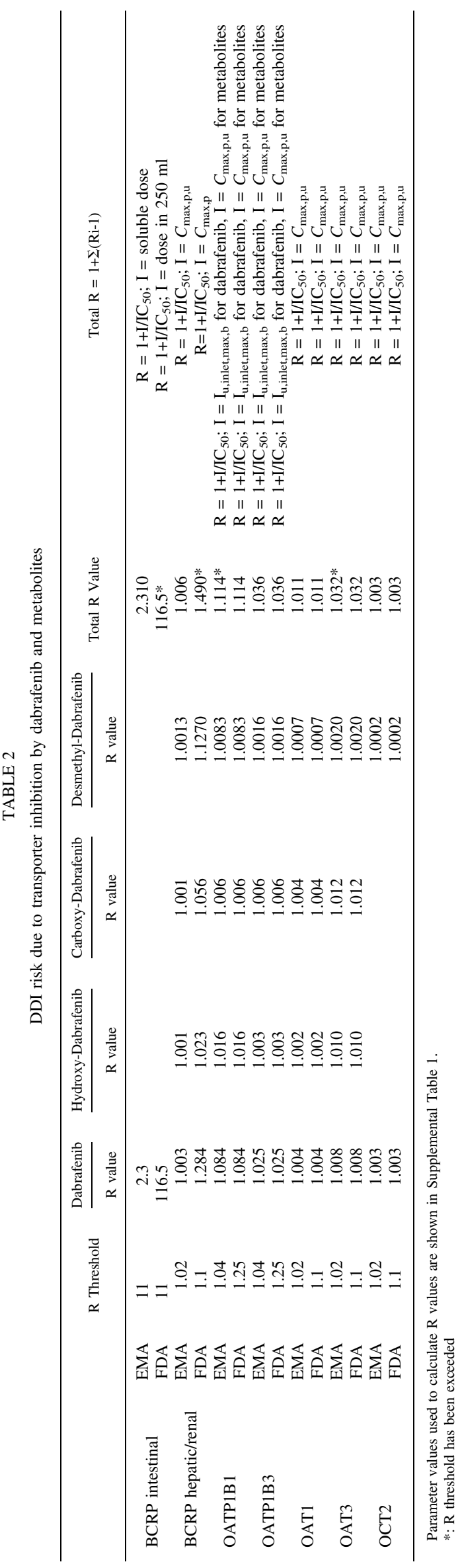


TABLE 3.

Permeability of dabrafenib and metabolites

\begin{tabular}{lccc}
\hline \multicolumn{1}{c}{ Compound } & A $\rightarrow$ B Papp $(\mathrm{nm} / \mathrm{s})$ & A $\rightarrow$ B Papp $(\mathrm{nm} / \mathrm{s})+$ GF120918 & Permeability Classification \\
\hline Dabrafenib & 16 & 150 & High \\
Hydroxy-Dabrafenib & 4.2 & 77 & High \\
Carboxy-Dabrafenib & 2.5 & 1.8 & Low \\
Desmethyl-Dabrafenib & 27 & 370 & High \\
Permeability Classification & & & \\
A-B Papp <5.0 & & & Low \\
50.0 > A-B Papp $>5.0$ & & & Moderate \\
A-B Papp $>$ 50.0 & & & High \\
\hline
\end{tabular}

Note that the presence of GF120918, the efflux ratio of dabrafenib and metabolites is $\sim 1$ (Table 4).

Determination of Kinetic Parameters for Active Transport. Kinetic parameters for active transport of hydroxy-dabrafenib, desmethyl-dabrafenib, and carboxy-dabrafenib were determined in cryopreserved human hepatocytes and OATP1B1, OATP1B3, and OATP1A2 cells, where appropriate (Ménochet et al., 2012). Hepatocytes were preincubated in triplicate at $37^{\circ} \mathrm{C}$ for 15 to 30 minutes in $1 \mathrm{ml}$ transport medium (DPBS with 1\% DMSO or DMF). Uptake of hydroxydabrafenib and desmethyl-dabrafenib (range 0.1-30 $\mu \mathrm{M}$ ) was then determined at $0.5,1,1.5,2,5,15,30$, and 60 minutes using multiple concentrations of each compound, whereas carboxy-dabrafenib (range 1-100 $\mu \mathrm{M}$ ) uptake was determined at $0.5,1.5,3,5,30,60,120$, and 180 minutes using multiple concentrations. Uptake kinetics of carboxy-dabrafenib were also determined in OATP1B1, OATP1B3, and OATP1A2 cells using multiple concentrations and time points (concentration ranges: $1-100 \mu \mathrm{M}$ for OATP1B1 and OATP1B3 and $0.5-50 \mu \mathrm{M}$ for OATP1A2; time points: $0.5,1.5,3,5,10,30,60$, and 120 minutes for OATP1B1; 0.5, 1, 1.5, 2, 5, 15, 30, and 60 minutes for OATP1B3; and $0.5,0.75,1,1.5,2,5,15$, and 30 minutes for OATP1A2). At the indicated time points, cells were washed rapidly with cold buffer as described above for OATP uptake studies and lysed with water. Concentrations of test compounds in the cell lysates were determined by LC/MS/MS. The kinetic parameters for active transport were determined as described in the calculations section below.

Transporter Uptake Studies (OAT1 and OAT3). Transporter-mediated uptake of carboxy-dabrafenib and positive control substrates $\left[{ }^{3} \mathrm{H}\right] \mathrm{PAH}$ (OAT1) and $\left[{ }^{3} \mathrm{H}\right] \mathrm{ES}$ (OAT3) was investigated using S2 cells expressing human OAT1 or OAT3 and S2 control cells. The cells were preincubated in triplicate for 15 minute at $37^{\circ} \mathrm{C}$ with $0.3 \mathrm{ml}$ of DPBS containing $0.1 \%$ DMSO. The uptake of carboxydabrafenib $(0.5,1,10$, and $100 \mu \mathrm{M})$ and $\left[{ }^{3} \mathrm{H}\right] \mathrm{PAH}(1 \mu \mathrm{M})$ or $\left[{ }^{3} \mathrm{H}\right] \mathrm{ES} 0.05 \mu \mathrm{M}$ was then determined at 1,2 , and 5 minutes in transporter expressing and control cells. After incubation, the cells were washed three times with $1 \mathrm{ml}$ of ice-cold DPBS and lysed in $0.5 \mathrm{ml}$ of purified water. Concentrations of the test compounds in the cell lysates were determined by LC/MS/MS or LSC as described above. Acceptable values for the OAT1 and OAT3 assays are cleared volume of each positive control substance in transporter expressing cells/cleared volume of each positive control substrate in control cells $\geq 4$.

\section{Sample Preparation and Analysis}

Samples containing dabrafenib, hydroxy-dabrafenib, or desmethyl-dabrafenib and the analytical internal standard $(50,75$, and $50 \mathrm{ng} / \mathrm{ml}$ stable isotopically labeled $\left[{ }^{2} \mathrm{H}_{9}\right]$ dabrafenib, $\left[{ }^{2} \mathrm{H}_{6}^{13} \mathrm{C}_{2}\right]$ hydroxy-dabrafenib, or $\left[{ }^{2} \mathrm{H}_{6}^{13} \mathrm{C}_{2}\right]$ desmethyldabrafenib in 50:50 acetonitrile:water, respectively) were extracted from lysates by liquid-liquid extraction with ethyl acetate, followed by LC/MS/MS analysis.

Samples containing carboxy-dabrafenib and the analytical internal standard (12 ng/ml $\left[{ }^{2} \mathrm{H}_{6}^{13} \mathrm{C}_{2}\right]$ carboxy-dabrafenib) were diluted using a solution of 80:20 ethyl alcohol:water, respectively, followed by LC/MS/MS analysis.

Cell lysates containing rosuvastatin and the analytical internal standard (stable isotopically labeled rosuvastatin $\left(25 \mathrm{ng} / \mathrm{ml}\left[{ }^{2} \mathrm{H}_{7}^{15} \mathrm{~N}_{2}\right]\right.$ rosuvastatin) in 50:50 acetonitrile:water) were extracted by liquid-liquid extraction with tert-butyl methyl ether, followed by LC/MS/MS analysis.

LC was performed using a Waters Acquity ultra high performance liquid chromatography (UPLC) system (Waters, Milford, MA). Chromatographic separation of dabrafenib, hydroxy-dabrafenib, desmethyl-dabrafenib, and rosuvastatin was obtained by using a gradient of $0.1 \%$ formic acid in water:acetonitrile on a Waters Acquity BEH C18 $(50 \times 2.1 \mathrm{~mm}, 1.7 \mu \mathrm{M})$ UPLC column. Chromatographic separation of carboxy-dabrafenib was achieved using a gradient of $0.1 \%$ formic acid in water: acetonitrile on a Waters Acquity BEH Phenyl $(50 \times 2.1 \mathrm{~mm}, 1.7 \mu \mathrm{M})$ UPLC column at $55^{\circ} \mathrm{C}$. Samples were analyzed by positive ion turbo ionspray MS/MS with an Applied Biosystems/MDS Sciex API 4000. The calibration range for dabrafenib, hydroxy-dabrafenib, desmethyl-dabrafenib, and rosuvastatin was 1 to $500 \mathrm{ng} / \mathrm{ml}$ and for carboxy-dabrafenib was 0.5 to $1000 \mathrm{ng} / \mathrm{ml}$. Typical run times were 1.5 minutes for dabrafenib, hydroxy-dabrafenib, and desmethyl-dabrafenib and 1.1 minutes for carboxy-dabrafenib. Raw data were integrated using Applied Biosystems/MDS Sciex software Analyst v 1.6.1. Analyst v 1.6.1 was used to calculate peak area ratios (a weighted $1 / \mathrm{x}^{2}$ linear regression was applied to analyte/internal standard peak area ratios versus analyte concentration data) to construct the calibration curves from which the concentrations of compound in the study samples were determined.

\section{Calculations}

Apparent passive permeability (Papp) was calculated using the following equation:

$$
P_{a p p}=\left(\frac{d C_{r}}{d t}\right) * \frac{V_{r}}{(A * C)}
$$

where $\mathrm{C}_{\mathrm{r}}$ is concentration in the receiver compartment, $\mathrm{V}_{\mathrm{r}}$ is the volume of the receiver compartment, $A$ is the surface area of the well $\left(1.13 \mathrm{~cm}^{2}\right.$ for 12 -well Transwell), $\mathrm{C}$ is the compound concentration in the dosing solution.

TABLE 4

Dabrafenib and metabolites as substrates of P-gp and BCRP

\begin{tabular}{|c|c|c|c|c|c|c|}
\hline \multirow{2}{*}{ Compound } & \multicolumn{2}{|c|}{ P-gP Efflux Ratio ${ }^{a}$} & \multicolumn{2}{|c|}{ BCRP Efflux Ratio $^{a}$} & \multirow{2}{*}{ P-gp Substrate } & \multirow{2}{*}{ BCRP Substrate } \\
\hline & No Inhibitor & + GF120918 & No Inhibitor & + GF120918 & & \\
\hline Dabrafenib & 36 & 1.0 & 3.6 & 1.3 & Yes & Yes \\
\hline Hydroxy-Dabrafenib & 120 & 1.0 & 13 & 1.3 & Yes & Yes \\
\hline Carboxy-Dabrafenib & 1.8 & 1.3 & 0.7 & 1.1 & No & No \\
\hline Desmethyl-Dabrafenib & 21 & 0.9 & 6.6 & 1.3 & Yes & Yes \\
\hline
\end{tabular}

${ }^{a}$ Efflux ratio equals $\left.\mathrm{P}_{\text {app }}[\mathrm{B} \rightarrow \mathrm{A}]\right) / \mathrm{P}_{\text {app }}[\mathrm{A} \rightarrow \mathrm{B}]$. A compound is considered a substrate when the efflux ratio is $>2$ in the absence of GF120918 and close to 1 in the presence of GF120918. 
$\mathrm{IC}_{50}$ values (the concentration of inhibitor required for $50 \%$ inhibition of the monolayer transport or cellular uptake) were determined using the following equation:

$$
y=\frac{\text { Range }}{1+\left(\frac{x}{\mathrm{IC}_{50}}\right)^{s}}+\text { Background }
$$

where $y$ is the transport or uptake rate as a percentage of the uninhibited control, Range is the maximum rate of transport (100\%) in the absence of inhibitor, Background is the uninhibitable transport rate as percentage of total rate, $x$ is the concentration of inhibitor $(\mu \mathrm{M})$ and $\mathrm{s}$ is the slope factor.

Kinetic parameters for transporter-mediated uptake into hepatocytes and cells heterologously expressing various OATPs as well as bidirectional passive diffusion clearance and $\mathrm{fu}_{\text {cell }}$ were determined according to Ménochet et al. (2012). The differential Eqs. 3 and 4 show the change in cell and media concentration over time, respectively, and were solved in MATLAB version 7.2 using the ODE45 solver.

$$
\begin{aligned}
\frac{d S_{c e l l}}{d t} & =\frac{\frac{V_{\max } \times \mathrm{S}_{\text {med,u }}}{K_{m, u} \times \mathrm{S}_{\text {med,u }}}+P_{\text {diff }, u} \times S_{\text {med }, u}-P_{\text {diff }, u} \times S_{\text {cell }} \times f u_{c e l l}}{V_{\text {cell }}} \\
\frac{d S_{\text {med }, u}}{d t} & =\frac{-\frac{V_{\text {max }} \times \mathrm{S}_{\text {med,u }}}{K_{m, u}+\mathrm{S}_{\text {med,u }}}-P_{\text {diff }, u} \times S_{\text {med }, u}+P_{\text {diff }, u} \times S_{\text {cell }} \times f u_{c e l l}}{V_{\text {med }}}
\end{aligned}
$$

where $\mathrm{S}_{\text {cell }}$ is intracellular concentration; $\mathrm{S}_{\mathrm{med}, \mathrm{u}}$ is unbound media concentrations; $K_{\mathrm{m}, \mathrm{u}}$ is unbound affinity constant; $V_{\max }$ is the maximum uptake rate; $\mathrm{P}_{\text {diff,u }}$ is the unbound passive diffusion clearance; $\mathrm{Fu}_{\mathrm{cell}}$ is the unbound intracellular fraction; $\mathrm{V}_{\text {cell }}$ is intracellular volume $\left(3.9 \mu \mathrm{l} / 10^{6}\right.$ cells used for hepatocyte experiments; 2.5 $\mu \mathrm{l} / 10^{6}$ cells used for OATP1B1 uptake experiments; $2.1 \mu \mathrm{l} / 10^{6}$ cells used for OATP1B3 uptake experiments; $2.0 \mu 1 / 10^{6}$ cells used for OATP1A2 uptake experiments. Information on calculation of cellular volume for HEK293 cells can be found in Supplemental Material); $V_{\text {med }}$ is media volume. The relationship between observed and predicted concentrations with $95 \%$ confidence intervals are shown in Supplemental Material.

\section{Quantitative DDI Risk Assessment}

The steady-state total $C_{\max }$ concentrations at the intended dose of $150 \mathrm{mg}$ (twice daily) were used as surrogates for the concentration of inhibitors $\left[I_{1}\right]$ (Clinical study BRF113683, data on file): $2.8 \mu \mathrm{M}$ for dabrafenib, $1.9 \mu \mathrm{M}$ for hydroxy-dabrafenib, $11 \mu \mathrm{M}$ for carboxy-dabrafenib, and $0.69 \mu \mathrm{M}$ for desmethyl-dabrafenib. The estimated concentration of dabrafenib in the gut $\left[\mathrm{I}_{2}\right]$ calculated as the dose of inhibitor in $250 \mathrm{ml}$ of water is $1155 \mu \mathrm{M}$. However, the maximal in vitro solubility of dabrafenib in simulated intestinal fluid in the fed state is only $13.1 \mu \mathrm{M}$.

Perpetrator DDI Risk of Dabrafenib and Metabolites. The potential impact of dabrafenib and its circulating metabolites hydroxy-dabrafenib, carboxydabrafenib, and desmethyl-dabrafenib on the human efflux transporters, breast cancer resistance protein (BCRP), and P-glycoprotein (P-gp) was determined as described in the FDA DDI guidance (FDA, 2012), such that further clinical evaluation of the risk is not necessary if $\left[\mathrm{I}_{1}\right] / \mathrm{IC}_{50}<0.1$ and $\left[\mathrm{I}_{2}\right] / \mathrm{IC}_{50}<10$. The DDI risk potential was also evaluated using the EMA guidance (EMA, 2012), where no further clinical risk assessment is required for intestinal efflux transporters if the $\mathrm{IC}_{50} \geq 0.1 *$ [maximum soluble concentration], which equals [maximum soluble concentration] $/ \mathrm{IC}_{50} \leq 10$ ) and for hepatic and renal efflux transporters if the $\mathrm{IC}_{50} \geq 50 * \mathrm{I}_{\mathrm{u}, \max }$. The potential impact of dabrafenib and circulating metabolites on the human hepatic uptake transporters (OATP1B1 and OATP1B3) was predicted using the $\mathrm{R}$ value approach $\left[\mathrm{R}=1+\left(\mathrm{fu} \times \mathrm{I}_{\text {inlet,max }} /\right.\right.$ $\left.\mathrm{IC}_{50}\right)$ as described by the FDA guidance, where no further clinical assessment is required if the $\mathrm{R}$ value $<1.25$, as well as the approach defined by the EMA guidance, where no further clinical assessment is needed if the $\mathrm{IC}_{50} \geq 25 * \mathrm{I}_{\mathrm{u} \text {,inlet,max }}$. $\mathrm{I}_{\text {inlet,max }}$ for dabrafenib was estimated as described in the guidances. The potential impact of dabrafenib and circulating metabolites on the human renal uptake transporters, OAT1 and OAT3, was determined according to the FDA guidance, where no clinical DDI study is required if the unbound $\mathrm{I}_{\text {max }} / \mathrm{IC}_{50}<$ 0.1 , and the EMA guidance, such that no further clinical studies are needed if the $\mathrm{IC}_{50} \geq 50 * \mathrm{I}_{\mathrm{u}, \max }$. The perpetrator risks were expressed as $\mathrm{R}$ values according to the equations listed in Table 2, and the risk for the combined inhibition by dabrafenib and metabolites was assessed by comparing the 'total $\mathrm{R}$ value' to the $\mathrm{R}$ value threshold (Table 2).
Victim DDI Risk of Dabrafenib Metabolites. The risk of a hepatic transporter-mediated victim DDI for dabrafenib metabolites could not be assessed based on metabolite levels in the feces, because carboxy-dabrafenib was shown to undergo decarboxylation to desmethyl dabrafenib in this matrix in preclinical species (Richards-Peterson et al., 2014). Therefore, the risk assessment was based on renal blood clearance $\left(\mathrm{CL}_{\mathrm{r}}\right)$ and hepatic blood clearance $\left(\mathrm{CL}_{\mathrm{h}}\right)$ of the metabolites. $\mathrm{CL}_{\mathrm{r}}$ was calculated from the human radiolabel study (amount excreted in urine/blood $\mathrm{AUC}$ ). $\mathrm{CL}_{\text {int,uptake }}$ for hepatic uptake was estimated by scaling up the in vitro hepatocyte uptake clearance (based on average initial uptake rates from 2-3 donors) to a liver weight of $1800 \mathrm{~g}$ (Barter et al., 2007) and $117.5 \times 10^{6}$ hepatocytes per gram liver (Barter et al., 2008). Hepatic blood clearance was calculated from the $\mathrm{CL}_{\text {int,uptake }}$ using the well-stirred model (Eq. 5), with liver blood flow (Q) being $97 \mathrm{l} / \mathrm{h}$ and values for the fraction unbound in blood $\left(f_{u, b}\right)$ based on fraction unbound in plasma $\left(f_{u, p}\right.$; set to 0.01 in case measured value of $\mathrm{f}_{\mathrm{u}, \mathrm{p}}$ is $<0.01$ ) and blood-to-plasma ratios from Supplemental Table 1.

$$
C L_{h}=\frac{\mathrm{Q} \times f_{u, b} \times C L_{\text {int }, \text { uptake }}}{\mathrm{Q}+\left(f_{u, b} \times C L_{\text {int }, \text { uptake }}\right)}
$$

The maximal fold increase resulting from complete inhibition of transportermediated uptake in the liver was calculated according to Eq. 6 (ZamekGliszczynski et al., 2009), where $\mathrm{f}_{\mathrm{t}}$ is the fraction cleared by hepatic uptake transport (Eq. 7) and $V_{\max }, K_{\mathrm{m}}$, and $\mathrm{P}_{\text {diff,u }}$ pertain to uptake into hepatocytes in vitro.

$$
\begin{gathered}
\text { fold } \Delta=\frac{1}{1-f_{t}} \\
f_{t}=\left[\frac{C L_{h}}{C L_{r}+C L_{h}}\right] \times\left[\frac{\frac{V \max }{K_{m}}}{\frac{V \max }{K_{m}}+P_{\text {diff }, u}}\right]
\end{gathered}
$$

\section{Results}

\section{In Vitro Transporter Inhibition Studies}

Inhibition of transport of $\left[{ }^{3} \mathrm{H}\right]$ digoxin and $\left[{ }^{14} \mathrm{C}\right]$ cimetidine by dabrafenib, hydroxy-dabrafenib, carboxy-dabrafenib, and desmethyldabrafenib was assessed in MDCKII-hMDR1 and MDCKII-hBCRP cell lines, respectively. Dabrafenib and circulating metabolites did not inhibit P-gp mediated digoxin transport at any concentration tested (Table 1). Hydroxy-dabrafenib and desmethyl-dabrafenib inhibited human BCRP-mediated cimetidine transport with $\mathrm{IC}_{50}$ values of 82 and $5.4 \mu \mathrm{M}$, respectively. Dabrafenib and carboxy-dabrafenib showed incomplete inhibition of BCRP at the highest test concentrations, 30 and $200 \mu \mathrm{M}$, respectively, and therefore an $\mathrm{IC}_{50}$ could not be determined (Table 1). The BCRP perpetrator risk for dabrafenib and metabolites is indicated in Table 2.

Inhibition of uptake of the OATP1B1 and OATP1B3 probe substrate $\left[{ }^{3} \mathrm{H}\right] \mathrm{EG}$ by dabrafenib, hydroxy-dabrafenib, carboxy-dabrafenib, and desmethyl-dabrafenib was investigated in cells overexpressing human OATP1B1 or OATP1B3. Dabrafenib, hydroxy-dabrafenib, carboxydabrafenib, and desmethyl-dabrafenib inhibited human OATP1B1 with $\mathrm{IC}_{50}$ values of $1.4,4.3,18$, and $0.83 \mu \mathrm{M}$, respectively, and OATP1B3 with $\mathrm{IC}_{50}$ values of $4.7,23,20$, and $4.3 \mu \mathrm{M}$, respectively (Table 1 ). The OATP perpetrator DDI risk was evaluated using the extrapolated R-value approach (FDA, 2012) as well as the approach recommended by the EMA (Table 2).

The inhibition of OAT1 and OAT3 by dabrafenib and its metabolites was investigated using 6-CFL as probe substrate in HEK-MSRII cells transduced with OAT1 or OAT3 BacMam baculovirus. For OAT1, IC 50 values of $6.9,29$, and $10 \mu \mathrm{M}$ were calculated for dabrafenib, hydroxydabrafenib, and desmethyl-dabrafenib, respectively. The degree of inhibition by carboxy-dabrafenib, up to $100 \mu \mathrm{M}$, was insufficient to calculate an $\mathrm{IC}_{50}$. For OAT3, $\mathrm{IC}_{50}$ values of $3.4,7.3,9.0$, and $3.4 \mu \mathrm{M}$ were calculated for dabrafenib, hydroxy-dabrafenib, carboxy-dabrafenib, 
and desmethyl-dabrafenib, respectively (Table 1). The inhibition of OCT2 by dabrafenib and metabolites was determined using $\left[{ }^{14} \mathrm{C}\right]$ metformin $(10 \mu \mathrm{M})$ as probe substrate. Hydroxy-dabrafenib and carboxy-dabrafenib did not inhibit OCT2-mediated transport of $\left[{ }^{14} \mathrm{C}\right]$ metformin up to $50 \mu \mathrm{M}$. Dabrafenib and desmethyl-dabrafenib inhibited OCT2-mediated transport of $\left[{ }^{14} \mathrm{C}\right]$ metformin with $\mathrm{IC}_{50}$ values of 9.3 and $28 \mu \mathrm{M}$, respectively (Table 1). The potential for dabrafenib and its circulating metabolites to cause a drug-drug interaction through inhibition of the renal transporters OAT1, OAT3, and OCT2 is shown in Table 2

\section{In Vitro Passive Permeability}

To assess the passive permeability of dabrafenib, hydroxy-dabrafenib, carboxy-dabrafenib, and desmethyl-dabrafenib, a single test compound concentration of $5 \mu \mathrm{M}$ was dosed in the presence of GF120918 (inhibitor of P-gp and BCRP) into the apical compartment of duplicate wells of MDCKII-hMDR1 cell monolayers grown in transwells. Dabrafenib, hydroxy-dabrafenib, and desmethyl-dabrafenib demonstrated high permeability with an apparent permeability $\left(\mathrm{P}_{\text {app }}\right)$ of 150,77 , and $370 \mathrm{~nm} / \mathrm{s}$, respectively (Table 3 ). Carboxy-dabrafenib exhibited low permeability with a $\mathrm{P}_{\text {app }}$ of $1.8 \mathrm{~nm} / \mathrm{s}$ (Table 3). Note that in the presence of GF120918, the efflux ratio of dabrafenib and metabolites in MDCKII-hMDR1 cells is approximately 1 (Table 4).

\section{In Vitro Transporter Phenotyping Studies}

Dabrafenib, hydroxy-dabrafenib, and desmethyl-dabrafenib were P-gp substrates with efflux ratios of 36,120 , and 21 , respectively, in MDCKII-hMDR1 cells, whereas carboxy-dabrafenib, with an efflux ratio of 1.8, was not considered a P-gp substrate. Additionally, dabrafenib, hydroxy-dabrafenib, and desmethyl-dabrafenib were substrates of human BCRP, with efflux ratios in MDCKII-hBCRP cells of 3.6, 13, and 6.6, respectively, whereas carboxy-dabrafenib with an efflux ratio of 0.7 was not considered a BCRP substrate (Table 4).

To identify the transport processes involved in the in vitro hepatic uptake, dabrafenib and its metabolites were incubated with cryopreserved human hepatocytes in the absence and presence of a transporter inhibitor cocktail (OATP and OCT1 inhibitors). Dabrafenib uptake in cryopreserved human hepatocytes was not inhibited by the transporter

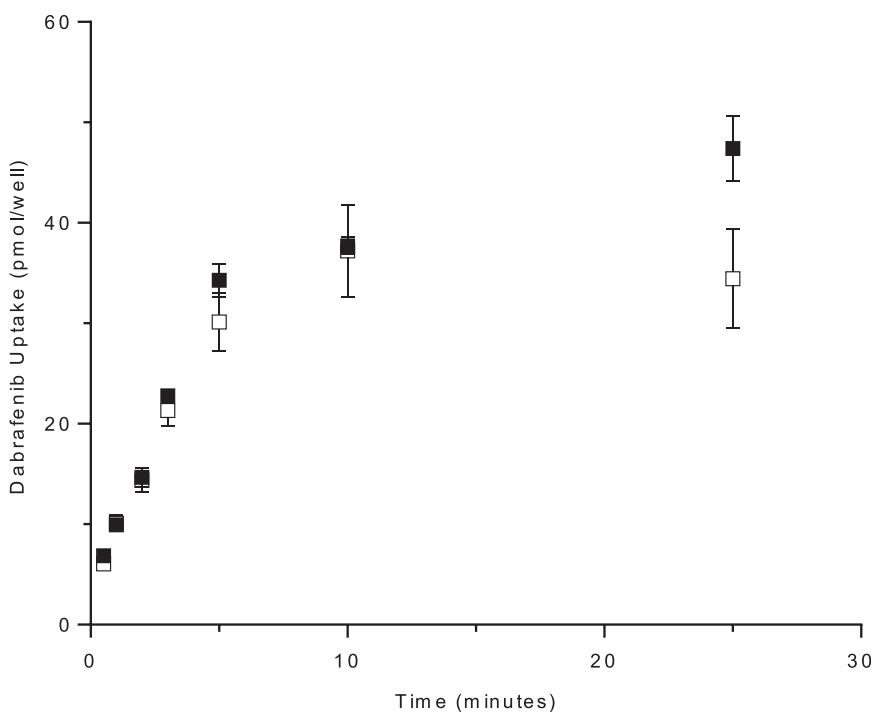

Fig. 2. Time-dependent transport of $0.3 \mu \mathrm{M}$ dabrafenib in cryopreserved human hepatocytes in the absence ( $\boldsymbol{\square}$ ) and presence of inhibitor cocktail (rifampicin SV, cyclosporine A, montelukast, and quinidine, at $10 \mu \mathrm{M}$ each) ( $\square$ ). inhibitor cocktail (Fig. 2), which, combined with its high passive permeability, is indicative of passive uptake of dabrafenib into hepatocytes, although, theoretically, active uptake of dabrafenib by a transporter or transport mechanism that is not inhibited by this inhibitor cocktail cannot be formally excluded. Uptake of hydroxy-dabrafenib and desmethyl-dabrafenib into cryopreserved human hepatocytes was partially inhibitable by the inhibitor cocktail (Figs. 3 and 5), indicating some involvement of transporters in the hepatic uptake of these metabolites. In contrast, the uptake of carboxy-dabrafenib was strongly inhibited, indicating that hepatic uptake of this metabolite occurs largely via a transporter-mediated process, consistent with its low passive permeability (Fig. 4). For Figs. 2-5, the results for only one substrate concentration are shown, because the other concentrations gave very similar results. Kinetic parameters for active uptake of hydroxydabrafenib, desmethyl-dabrafenib, and carboxy-dabrafenib in cryopreserved hepatocytes (using a single lot of cryopreserved hepatocytes only) were obtained using the mathematical model described in Materials and Methods and are shown in Table 5 (see also Supplemental Tables 1-3). Fits of the model to the data and the associated 95\% CI are shown in Supplemental Figs. 1-3 and Supplemental Appendices 1-3. Although the potential for further metabolism of hydroxy-dabrafenib and carboxy-dabrafenib in the hepatocytes exists in vitro, good fits to the data suggest that incorporation of a metabolism component is not required, indicating that further metabolism is negligible during the relatively short incubation period.

To determine which transporters were responsible for uptake of hydroxy- and desmethyl-dabrafenib into hepatocytes, these metabolites were subsequently incubated with OATP1B1- and OATP1B3-expressing cells in the absence and presence of $10 \mu \mathrm{M}$ rifamycin (OATP1B1 and OATP1B3 inhibitor). They were also investigated as substrates in OATP1A2- or OATP2B1-expressing cells in the absence and presence of $10 \mu \mathrm{M}$ ketoconazole (OATP1A2 inhibitor) or $10 \mu \mathrm{M}$ montelukast (OATP2B1 inhibitor). Uptake of the metabolites was not inhibited by these inhibitors and, therefore, these metabolites are most likely not substrates of OATP1B1, OATP1B3, OATP2B1, or OATP1A2. Uptake of hydroxy- and desmethyl-dabrafenib into hepatocytes was also not inhibited by $100 \mu \mathrm{M}$ imipramine, indicating they are likely not substrates of OCT1 either. The caveat here is that we cannot formally exclude the possibility that, although

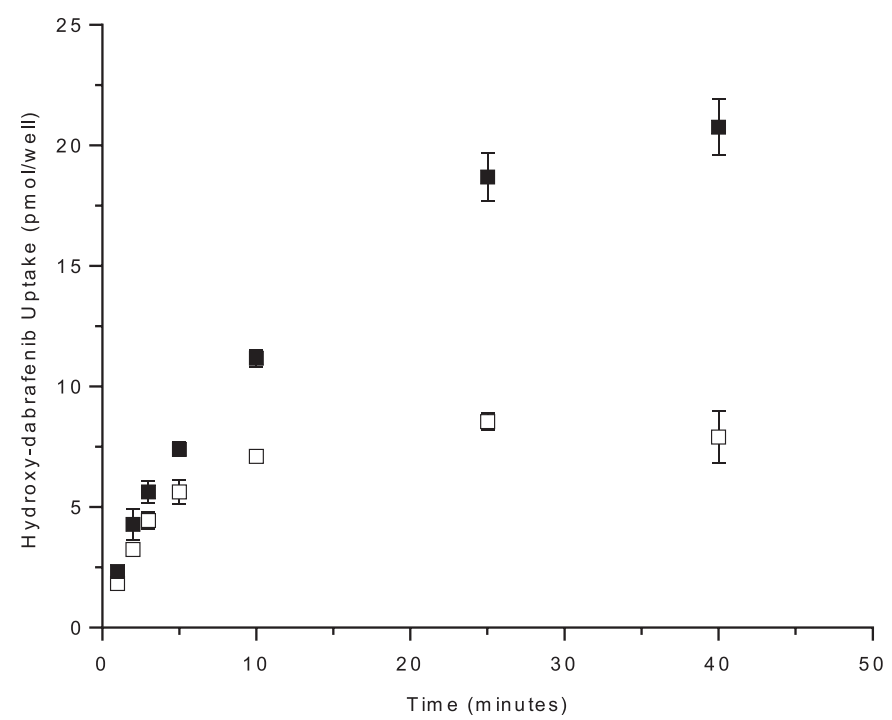

Fig. 3. Time-dependent transport of $0.5 \mu \mathrm{M}$ hydroxy-dabrafenib in cryopreserved human hepatocytes in the absence (ם) and presence of inhibitor cocktail (rifampicin $\mathrm{SV}$, cyclosporine A, montelukast, and quinidine, at $10 \mu \mathrm{M}$ each) ( $\square$ ). 


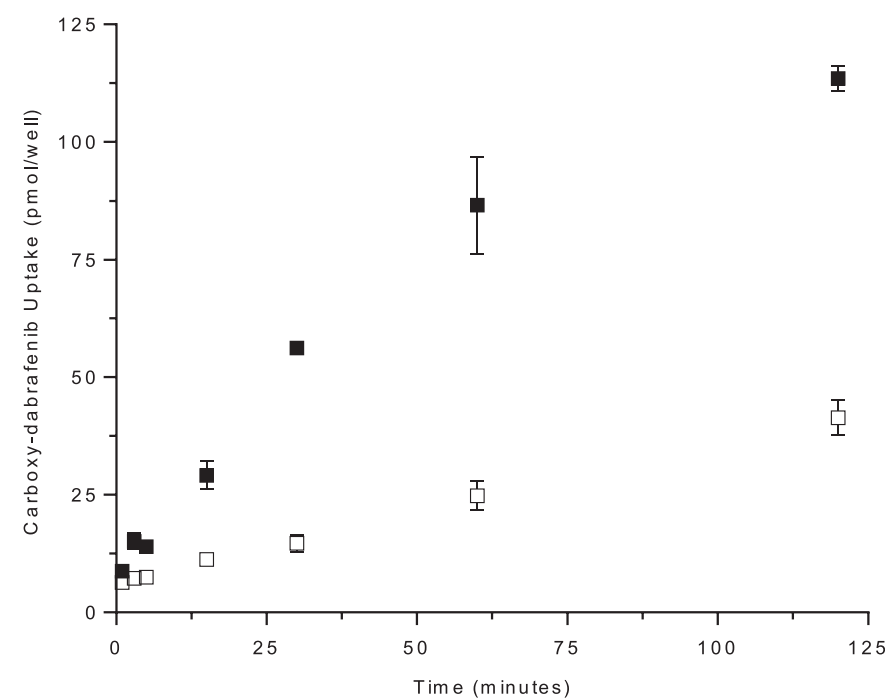

Fig. 4. Time-dependent transport of $30 \mu \mathrm{M}$ carboxy-dabrafenib in cryopreserved human hepatocytes in the absence (ם) and presence of inhibitor cocktail (rifampicin $\mathrm{SV}$, cyclosporine A, montelukast, and quinidine, at $10 \mu \mathrm{M}$ each) ( $\square$ ).

the various inhibitors inhibit the uptake of the respective probe substrates for each of these transporters, they do not inhibit the uptake of hydroxyand desmethyl-dabrafenib due to the existence of completely independent binding sites for the respective inhibitors and these two metabolites.

Carboxy-dabrafenib on the other hand was shown to be a substrate of OATP1B1, OATP1B3, and OATP1A2, because uptake in transporter expressing cells was inhibitable by the respective transporter inhibitors. Kinetic parameters were therefore determined and are shown in Table 5 (see also Supplemental Tables 4-6). Fits to the data and fit statistics are shown in Supplemental Figs. 4-6 and Supplemental Appendices 4-6.

Because a substantial fraction of carboxy-dabrafenib is eliminated via the kidney, this metabolite was also investigated as a substrate of renal OATs. Comparison of the uptake in control S2 cells and S2 cells expressing human OAT1 or OAT3 (Kimura et al., 2002) showed signalto-noise ratios of up to 4 and 14, respectively, indicating that carboxydabrafenib was a substrate of both transporters. Positive control substrate (6-CFL) signal-to-noise ratios were 65 and 10 for OAT1 and OAT3, respectively. Kinetic parameters were not determined.

\section{Discussion}

In the present study, we investigated the potential for dabrafenib and its circulating metabolites to interact with clinically relevant uptake and/ or efflux transporters in the intestine, liver, and kidney. To assess the perpetrator DDI risk, the in vitro inhibition of P-gp, BCRP, OATP1B1, OATP1B3, OAT1, OAT3, and OCT2 was determined (Table 1). Although an $\mathrm{IC}_{50}$ value for BCRP inhibition could not be determined, a risk was identified for inhibition of intestinal BCRP according to the criterion listed in the FDA guidance. Dabrafenib inhibited BCRP by $52 \%$ at $10 \mu \mathrm{M}$. Assuming an $\mathrm{IC}_{50}$ of $10 \mu \mathrm{M}$ results in an $\mathrm{I}_{2} / \mathrm{IC}_{50}$ value of $[1155 \mu \mathrm{M} / 10 \mu \mathrm{M}]=115.5$, well above the risk threshold. However, the maximal in vitro solubility of dabrafenib in simulated intestinal fluid in the fed state is only $13.1 \mu \mathrm{M}$. Therefore, according to the EMA guidance, there is no risk for intestinal BCRP inhibition because the $\mathrm{IC}_{50} \geq 0.1 *[$ maximum soluble concentration $]=0.1 * 13.1=1.31 \mu \mathrm{M}$ (Table 2). Given the limited solubility of dabrafenib in simulated intestinal fluid, the risk for inhibition of intestinal BCRP appears low.

Dabrafenib and its metabolites demonstrated a slight risk for inhibition of hepatic or renal BCRP with a total $\mathrm{R}$ value according to the

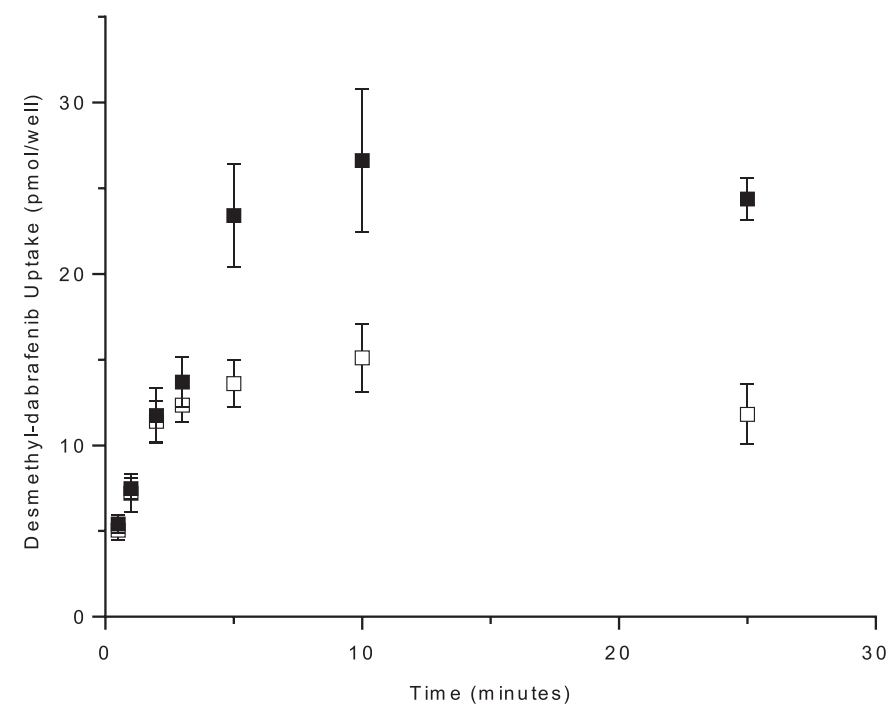

Fig. 5. Time-dependent transport of $0.3 \mu \mathrm{M}$ desmethyl-dabrafenib in cryopreserved human hepatocytes in the absence $(\boldsymbol{\square})$ and presence of inhibitor cocktail (rifampicin $\mathrm{SV}$, cyclosporine A, montelukast, and quinidine, at $10 \mu \mathrm{M}$ each) ( $\square$ ).

FDA guidance of 1.49 , above the threshold value of 1.1 , whereas the total $\mathrm{R}$ value according to the EMA guidance was 1.006, below the threshold of 1.02 (Table 2). A slight risk for inhibition of OATP1B1 by dabrafenib and its metabolites was identified by the EMA, but not the FDA criteria (Table 2). A very slight risk was also identified for inhibition of OAT3 with the total R value just above the EMA but below the FDA threshold value (Table 2). A clinical DDI study probing the effect of dabrafenib and metabolites on the BCRP, OATP1B1, and OAT3 substrate rosuvastatin is currently ongoing. However, because rosuvastatin is a substrate of multiple transporters, mechanistic extrapolation of such a clinical study to other substrates of these transporters may be difficult (Elsby et al., 2012).

Dabrafenib, hydroxy-dabrafenib. and desmethyl-dabrafenib were shown to have high passive permeability and to be substrates of the efflux transporters P-gp and BCRP, whereas carboxy-dabrafenib, with very low passive permeability, was a substrate of several OATPs and OATs. The oral bioavailability of dabrafenib is $95 \%$, indicative of extensive absorption and low first pass intestinal and hepatic metabolism (Denton et al., 2013). Although dabrafenib is a substrate of P-gp and BCRP, these efflux transporters do not limit the extent of dabrafenib absorption, likely resulting from the high passive permeability of this compound. These transporters may however contribute to the suggested prolonged absorption of dabrafenib (flip-flop kinetics) (Denton et al., 2013).

Formation of hydroxy-dabrafenib is mediated by CYP2C8 and CYP3A4 and that of carboxy-dabrafenib by CYP3A4 only. Given the high bioavailability and consequently low first-pass metabolic clearance, formation of these metabolites is expected to occur mainly in the liver. Desmethyl-dabrafenib can be formed as a product of nonenzymatic decarboxylation of carboxy-dabrafenib under low $\mathrm{pH}$ conditions ( $\leq$ pH 5) (Bershas et al., 2013). It is formed in hepatocytes in vitro, possibly in endosomes or lysosomes throughout the body (to the extent this low permeability metabolite can gain access to these membranebound compartments), but contribution from cytoplasmic enzymes cannot be ruled out. P-gp and BCRP likely contribute to the biliary excretion of dabrafenib, hydroxy-, and desmethyl-dabrafenib. A relevant effect of a P-gp or BCRP inhibitor on the clearance of dabrafenib is unlikely because the compound is eliminated predominantly by metabolism. This is indicated by the limited fecal excretion of unchanged 
TABLE 5

Kinetic parameters for active uptake of dabrafenib metabolites by OATPs

\begin{tabular}{|c|c|c|c|c|c|c|c|c|c|}
\hline & \multicolumn{3}{|c|}{ Hydroxy-Dabrafenib } & \multicolumn{3}{|c|}{ Carboxy-Dabrafenib } & \multicolumn{3}{|c|}{ Desmethyl-Dabrafenib } \\
\hline & $\mathrm{Km}$ & Vmax & Pdiff,u & $\mathrm{Km}$ & Vmax & Pdiff,u & $\mathrm{Km}$ & Vmax & Pdiff,u \\
\hline & $\mu M$ & $\mathrm{pmol} / \mathrm{min} / 10^{6}$ cells & $\mu \mathrm{l} / \mathrm{min} / 10^{6} \mathrm{cells}$ & $\mu M$ & $\mathrm{pmol} / \mathrm{min} / 10^{6}$ cells & $\mu \mathrm{l} / \mathrm{min} / 10^{6}$ cells & $\mu M$ & $\mathrm{pmol} / \mathrm{min} / 10^{6} \mathrm{cells}$ & $\mu \mathrm{l} / \mathrm{min} / 10^{6}$ cells \\
\hline Hepatocytes & $0.99 \pm 0.26$ & $11 \pm 2.5$ & 5.1 & $2.3 \pm 0.40$ & $9.4 \pm 0.89$ & 0.092 & $1.8 \pm 0.56$ & $62 \pm 19$ & 21 \\
\hline OATP1B1 & & Not a substrate & & $15 \pm 3.1$ & $48 \pm 10$ & 0.19 & & Not a substrate & \\
\hline OATP1B3 & & Not a substrate & & $3.0 \pm 0.96$ & $12 \pm 2.6$ & 0.42 & & Not a substrate & \\
\hline OATP1A2 & & Not a substrate & & $2.0 \pm 1.5$ & $0.88 \pm 0.46$ & 0.28 & & Not a substrate & \\
\hline
\end{tabular}

$\mathrm{P}_{\mathrm{diff}, \mathrm{u}}$, unbound passive diffusion clearance.

dabrafenib (21.8\%) and the absence of biliary secretion in rat (RichardsPeterson et al., 2014) or mouse. Hydroxy-dabrafenib is eliminated predominantly by further oxidation to carboxy-dabrafenib and seems unlikely to undergo significant efflux, suggested by its low fecal excretion $(4.52 \%$ of the dose after oral administration, Supplemental Table 1 in Bershas et al., 2013). Hence, no significant DDI effect of a P-gp or BCRP inhibitor is expected. Desmethyl-dabrafenib may be cleared to a significant extent by P-gp and BCRP-mediated biliary or intestinal secretion, but is also further metabolized to several minor metabolites and renally cleared to a limited extent. A DDI effect of a potent dual P-gp and BCRP inhibitor on the clearance desmethyldabrafenib cannot be excluded but is expected to be limited. Carboxydabrafenib is one of the main metabolites in the feces. Given that MRP transporters are known to transport amphiphilic organic anions (Keppler, 2011), biliary secretion of carboxy-dabrafenib may involve MRP2, but this was not further investigated. The basolateral secretion of hydroxy- and desmethyl-dabrafenib from hepatocytes into blood is likely to occur at least in part via passive diffusion. Given its very low passive permeability, secretion of carboxy-dabrafenib into the blood might involve a transporter, possibly of the MRP family (not further investigated).

Even compounds that are largely eliminated via hepatic metabolism and/or biliary excretion, such as dabrafenib, may be susceptible to pharmacokinetic drug interactions through inhibition of hepatic uptake transporters. For example, atorvastatin is almost completely metabolized by CYP3A4. However, pharmacogenetic studies have demonstrated that OATP1B1 plays an important role in hepatic elimination of atorvastatin by determining the rate of hepatic uptake and therefore influencing the pharmacokinetics of this drug (Maeda et al., 2011; Elsby et al., 2012). Dabrafenib and its major circulating metabolites were therefore investigated as substrates of hepatic uptake transporters.

In line with its high passive permeability, dabrafenib uptake in hepatocytes in vitro was not inhibitable by inhibitors of OATPs and
OCT1 and therefore did not appear to involve uptake transporters. Both hydroxy- and desmethyl-dabrafenib showed some evidence of a saturable uptake process, in addition to passive permeability. The kinetic parameters for active uptake of these metabolites were determined using a single lot of cryopreserved hepatocytes. The active uptake clearance $\left(V_{\max } / K_{\mathrm{m}}\right)$ for hydroxy-dabrafenib $\left(11 \mu \mathrm{l} / \mathrm{min} / 10^{6}\right.$ cells) was about twofold greater than the unbound passive diffusion clearance, whereas that of desmethyldabrafenib (34 $\mu \mathrm{l} / \mathrm{min} / 10^{6}$ cells) was 1.6 -fold greater. Further transporter phenotyping studies with individually expressed transporters showed that these metabolites were not substrates of OATP1B1, OATP1B3, OATP1A2, OATP2B1, or OCT1, hence the uptake transporter(s) involved in hepatocyte uptake of these metabolites remain(s) unidentified.

The uptake of carboxy-dabrafenib in hepatocytes was almost completely inhibited by a cocktail of OATP and OCT1 inhibitors. The active uptake clearance was $4.1 \mu \mathrm{l} / \mathrm{min} / 10^{6}$ cells, 45 -fold greater than the unbound passive diffusion clearance (determined in the same single lot of cryopreserved hepatocytes as hydroxy- and desmethyldabrafenib). Further studies showed that it was indeed a substrate of OATP1B1, OATP1B3, and OATP1A2 overexpressed in HEK cells. This is in line with the structural class of this metabolite and its low passive permeability. Carboxy-dabrafenib was also shown to be a substrate of OAT1 and OAT3. No major change in exposure to carboxy-dabrafenib is expected upon inhibition of OAT1 and/or OAT3, because active renal secretion is only one of several elimination pathways, which also include glomerular filtration, fecal elimination, and possibly clearance via extrahepatic decarboxylation.

Hydroxy-dabrafenib, carboxy-dabrafenib, and desmethyl-dabrafenib are eliminated via metabolism as well as renal and biliary secretion. The renal clearance of the metabolites $\left(\mathrm{Xe}_{0-t} / \mathrm{AUC}_{0-t}\right)$ (Table 6) was calculated from the human radiolabel study (Bershas et al., 2013), whereas the hepatic clearance was estimated by scaling in vitro $\mathrm{CL}_{\text {int }}$ for hepatocyte uptake to whole liver using a well stirred model (Table 6).

TABLE 6

Assessment of worst case DDI risk for carboxy-dabrafenib due to inhibition of hepatic uptake transport

\begin{tabular}{|c|c|c|c|c|c|c|}
\hline & $\begin{array}{c}\text { Renal } \\
\text { Blood Clearance }{ }^{a}\end{array}$ & $\begin{array}{l}\text { In Vitro Hepatocyte } \\
\text { Uptake Clearance }\end{array}$ & $\begin{array}{l}\text { In Vitro Hepatocyte } \\
\text { Uptake Clearance }^{c}\end{array}$ & $\begin{array}{c}\text { Hepatic } \\
\text { CLint,uptake }^{d}\end{array}$ & $\begin{array}{c}\text { Hepatic } \\
\text { Blood Clearance }^{e}\end{array}$ & $\begin{array}{l}\text { Worst Case Increase in Exposure upon } \\
\text { Complete Inhibition of Hepatic Uptake Transport }\end{array}$ \\
\hline & $\mathrm{ml} / \mathrm{h}$ & $\mu \mathrm{l} / \mathrm{min} / 10^{6} \mathrm{cells}$ & $\mu \mathrm{l} / \mathrm{min} / 10^{6} \mathrm{cells}$ & $l / h$ & $m l / h$ & \\
\hline Hydroxy-dabrafenib & 468 & 16.2 & $9.2(7.7,10.6)$ & 116 & $\mathrm{NC}$ & \multirow{3}{*}{1.9} \\
\hline Carboxy-dabrafenib & 390 & 4.2 & $1.4(1.7,0.6,2.1)$ & 18 & 362 & \\
\hline Desmethyl-dabrafenib & 2160 & 55.4 & $18.8(27.7,10.0)$ & 239 & $\mathrm{NC}$ & \\
\hline
\end{tabular}

NC, not calculated.

${ }^{a}$ Amount excreted in urine/AUC(blood) from the human radiolabel study (Bershas et al., 2013).

${ }^{b}$ Based on single determination of $K_{\mathrm{m}}, V_{\mathrm{max}}$, and $\mathrm{P}_{\mathrm{diff}, u}$

${ }^{c}$ Calculated from initial uptake rates at concentrations at or below the relevant $K_{\mathrm{m}}$ indicated in Table 5. Numbers in parentheses are values for individual donors.

${ }^{d} \mathrm{CL}_{\text {int,uptake }}$ was determined by scaling in vitro uptake clearance calculated based on initial uptake rates (c) to whole liver assuming liver weight of $1800 \mathrm{~g}$ and $117.5 \times 10^{6}$ hepatocytes/g liver (Barter et al., 2007,2008).

${ }^{e} \mathrm{CL}_{\mathrm{h}}=\mathrm{Q}_{\mathrm{h}} \times \mathrm{f}_{\mathrm{u}, \mathrm{b}} \times \mathrm{CL}_{\text {int,uptake }} / \mathrm{Q}_{\mathrm{h}}+\mathrm{f}_{\mathrm{u}, \mathrm{b}} \times \mathrm{CL}_{\text {int,uptake }}$

${ }^{f}$ Maximal fold increase equal $1 / 1-\mathrm{ft}$ (Zamek-Gliszczynski et al., 2009). Calculated based on fractional liver clearance (liver clearance/total clearance) and in vitro hepatocyte $\mathrm{ft}$ (active uptake clearance/total uptake clearance). 
The potential worst case magnitude of the increase in exposure upon complete inhibition of hepatic uptake transport for carboxy-dabrafenib was estimated to be 1.9-fold, according to Eq. 6 (Zamek-Gliszczynski et al., 2009), taking into account the limiting effects of both renal clearance and passive diffusion into hepatocytes. This is clearly an overestimate because the second term in Eq. 7 only considers hepatic uptake and assumes metabolism plus biliary secretion is sufficiently fast to not affect the total hepatic intrinsic clearance significantly, which may not be the case given the $\mathrm{CL}_{\text {int }}$ value measured in human liver microsomes $(<0.009 \mathrm{ml} / \mathrm{min} / \mathrm{mg}$ microsomal protein, data on file). This risk may be further limited by the potential for extrahepatic decarboxylation of carboxy-dabrafenib. Because the $\mathrm{CL}_{\text {int,uptake }}$ for hepatic uptake of hydroxyand desmethyl-dabrafenib was greater than liver blood flow (Table 6), the effect of transport inhibition is likely low.

In summary, the current work has provided insight into the role of transporters in the disposition of dabrafenib and its major circulating metabolites as well as their possible effects on coadministered transporter substrate drugs. These data indicate a low perpetrator DDI risk for dabrafenib and/or metabolites, which is currently being investigated in a clinical DDI study. No victim DDI risk was identified for dabrafenib. Although a small increase in exposure to carboxy-dabrafenib upon inhibition of OATPs and an increase in exposure to desmethyldabrafenib upon inhibition of P-gp or BCRP cannot be excluded, the clinical significance of such increases is likely to be low.

\section{Acknowledgments}

The authors wish to acknowledge Elisabeth Minthorne for generating passive permeability and P-gp substrate data for dabrafenib and metabolites and Valeriu Damian-Iordache for MatLab support. The authors also thank Maciej ZamekGliszczynski for helpful suggestions as well as Markus Zollinger and Annie St. Pierre for helpful suggestions and critical reading of the manuscript.

\section{Authorship Contributions}

Participated in research design: Ellens, Johnson, Lawrence, Watson, Chen, Richards-Peterson.

Conducted experiments: Johnson, Watson

Performed data analysis: Ellens, Johnson, Lawrence.

Wrote or contributed to the writing of the manuscript: Ellens, Johnson, Lawrence.

\section{References}

Barter ZE, Bayliss MK, Beaune PH, Boobis AR, Carlile DJ, Edwards RJ, Houston JB, Lake BG, Lipscomb JC, Pelkonen OR, et al. (2007) Scaling factors for the extrapolation of in vivo metabolic drug clearance from in vitro data: reaching a consensus on values of human microsomal protein and hepatocellularity per gram of liver. Curr Drug Metab 8:33-45.

Barter ZE, Chowdry JE, Harlow JR, Snawder JE, Lipscomb JC, and Rostami-Hodjegan A (2008) Covariation of human microsomal protein per gram of liver with age: absence of influence of operator and sample storage may justify interlaboratory data pooling. Drug Metab Dispos 36 2405-2409.

Bershas DA, Ouellet D, Mamaril-Fishman DB, Nebot N, Carson SW, Blackman SC, Morrison RA Adams JL, Jurusik KE, Knecht DM, et al. (2013) Metabolism and disposition of oral dabrafenib in cancer patients: proposed participation of aryl nitrogen in carbon-carbon bond cleavage via decarboxylation following enzymatic oxidation. Drug Metab Dispos 41:2215-2224.

Davies H, Bignell GR, Cox C, Stephens P, Edkins S, Clegg S, Teague J, Woffendin H, Garnett MJ, Bottomley W, et al. (2002) Mutations of the BRAF gene in human cancer. Nature 417 949-954.

Denton CL, Minthorn E, Carson SW, Young GC, Richards-Peterson LE, Botbyl J, Han C, Morrison RA, Blackman SC, and Ouellet D (2013) Concomitant oral and intravenous pharmacokinetics of dabrafenib, a BRAF inhibitor, in patients with BRAF V600 mutation-positive solid tumors. J Clin Pharmacol 53:955-961.

Dossett LA, Kudchadkar RR, and Zager JS (2015) BRAF and MEK inhibition in melanoma. Expert Opin Drug Saf 14:559-570.
Eggermont AM and Robert C (2011) New drugs in melanoma: it's a whole new world. Eur J Cancer 47:2150-2157.

Elsby R, Fox L, Stresser D, Layton M, Butters C, Sharma P, Smith V, and Surry D (2011) In vitro risk assessment of AZD9056 perpetrating a transporter-mediated drug-drug interaction with methotrexate. Eur J Pharm Sci 43:41-49.

Elsby R, Hilgendorf C, and Fenner K (2012) Understanding the critical disposition pathways of statins to assess drug-drug interaction risk during drug development: it's not just about OATP1B1. Clin Pharmacol Ther 92:584-598.

EMA(2012) Guideline on the Investigation of Drug Interactions, rev 1 corr 2. European Medicines Agency, London.

Falchook GS, Long GV, Kurzrock R, Kim KB, Arkenau TH, Brown MP, Hamid O, Infante JR, Millward M, Pavlick AC, et al. (2012) Dabrafenib in patients with melanoma, untreated brain metastases, and other solid tumours: a phase 1 dose-escalation trial. Lancet 379:1893-1901.

FDA(2012) Drug Interaction Studies-Study Design, Data Analysis, Implications for Dosing, and Labeling Recommendations. Food and Drug Administration, Silver Spring.

Flaherty KT and McArthur G (2010) BRAF, a target in melanoma: implications for solid tumor drug development. Cancer 116:4902-4913.

Giacomini KM, Huang SM, Tweedie DJ, Benet LZ, Brouwer KL, Chu X, Dahlin A, Evers R, Fischer V, Hillgren KM, et al.; International Transporter Consortium (2010) Membrane transporters in drug development. Nat Rev Drug Discov 9:215-236.

Han HK (2011) Role of transporters in drug interactions. Arch Pharm Res 34:1865-1877.

Hauschild A, Grob JJ, Demidov LV, Jouary T, Gutzmer R, Millward M, Rutkowski P, Blank CU, Miller WH, Jr, Kaempgen E, et al. (2012) Dabrafenib in BRAF-mutated metastatic melanoma: a multicentre, open-label, phase 3 randomised controlled trial. Lancet 380:358-365.

Heakal Y, Kester M, and Savage S (2011) Vemurafenib (PLX4032): an orally available inhibitor of mutated BRAF for the treatment of metastatic melanoma. Ann Pharmacother 45:1399-1405.

Keppler D (2011) Multidrug resistance proteins (MRPs, ABCCs): importance for pathophysiology and drug therapy. Handb Exp Pharmacol 201:299-323.

Kimura H, Takeda M, Narikawa S, Enomoto A, Ichida K, and Endou H (2002) Human organic anion transporters and human organic cation transporters mediate renal transport of prostaglandins. J Pharmacol Exp Ther 301:293-298.

Kost TA, Condreay JP, and Ames RS (2010) Baculovirus gene delivery: a flexible assay development tool. Curr Gene Ther 10:168-173.

Lawrence SK, Nguyen D, Bowen C, Richards-Peterson L, and Skordos KW (2014) The metabolic drug-drug interaction profile of Dabrafenib: in vitro investigations and quantitative extrapolation of the P450-mediated DDI risk. Drug Metab Dispos 42:1180-1190.

Maeda K, Ikeda Y, Fujita T, Yoshida K, Azuma Y, Haruyama Y, Yamane N, Kumagai Y, and Sugiyama $Y$ (2011) Identification of the rate-determining process in the hepatic clearance of atorvastatin in a clinical cassette microdosing study. Clin Pharmacol Ther 90:575-581.

Ménochet K, Kenworthy KE, Houston JB, and Galetin A (2012) Simultaneous assessment of uptake and metabolism in rat hepatocytes: a comprehensive mechanistic model. J Pharmacol Exp Ther 341:2-15

Menzies AM and Long GV (2014) Dabrafenib and trametinib, alone and in combination for BRAFmutant metastatic melanoma. Clin Cancer Res 20:2035-2043.

Reese MJ, Bowers GD, Humphreys JE, Gould EP, Ford SL, Webster LO, and Polli JW (2016) Drug interaction profile of the HIV integrase inhibitor cabotegravir: assessment from in vitro studies and a clinical investigation with midazolam. Xenobiotica 46:445-456.

Richards-Peterson L, Wilde T, Mamaril-Fishman D, Bershas D, Karlinsey M, Schubert E, Castellino S, Ouellet D, and Gorycki P (2014) Disposition and metabolism of $\left[{ }^{14} \mathrm{C}\right]$ dabrafenib, a RAF kinase inhibitor, in mice, rats, dogs and humans, in Abstracts from the 10th International ISSX Meeting. Drug Metab Rev 45 (S1):313.

Robert C, Karaszewska B, Schachter J, Rutkowski P, Mackiewicz A, Stroiakovski D, Lichinitser M, Dummer R, Grange F, Mortier L, et al. (2015) Improved overall survival in melanoma with combined dabrafenib and trametinib. $N$ Engl J Med 372:30-39.

Roberts PJ and Der CJ (2007) Targeting the Raf-MEK-ERK mitogen-activated protein kinase cascade for the treatment of cancer. Oncogene 26:3291-3310.

Shirasaka Y, Mori T, Shichiri M, Nakanishi T, and Tamai I (2012) Functional pleiotropy of organic anion transporting polypeptide OATP2B1 due to multiple binding sites. Drug Metab Pharmacokinet 27:360-364.

Suttle AB, Richards-Peterson L, Ouellet D, Aktan G, Gordon M, LoRusso P, Infante JR, Sharma S, Kendra K, Patel M, Arkenau H-T, et al. (2014) A study of the effects of inhibition of CYP3A4 by ketoconazole $(\mathrm{K})$ and $\mathrm{CYP} 2 \mathrm{C} 8$ by gemfibrozil $(\mathrm{G})$ on the pharmacokinetics of Dabrafenib (D). Clin Pharmacol Ther, 95:S89.

Ugurel S, Röhmel J, Ascierto PA, Flaherty KT, Grob JJ, Hauschild A, Larkin J, Long GV, Lorigan P, McArthur GA, et al. (2016) Survival of patients with advanced metastatic melanoma: The impact of novel therapies. Eur J Cancer 53:125-134.

Umehara KI, Iwatsubo T, Noguchi K, Usui T, and Kamimura H (2008) Effect of cationic drugs on the transporting activity of human and rat OCT/Oct 1-3 in vitro and implications for drug-drug interactions. Xenobiotica 38:1203-1218.

Zamek-Gliszczynski MJ, Kalvass JC, Pollack GM, and Brouwer KL (2009) Relationship between drug/ metabolite exposure and impairment of excretory transport function. Drug Metab Dispos 37:386-390.

Zhang L, Huang SM, and Lesko LJ (2011) Transporter-mediated drug-drug interactions. Clin Pharmacol Ther 89:481-484.

Address correspondence to: Dr. Harma M. Ellens (c/o Dr. Marta Johnson), GlaxoSmithKline, Drug Metabolism and Pharmacokinetics, 709 Swedeland Rd., King of Prussia, PA 19406. E-mail: harmaellens@gmail.com 